\title{
NiAl-Cr-Mo Medium Entropy Alloys: Microstructural Verification, Solidification Considerations, and Sliding Wear Response
}

\author{
Christina Mathiou, Konstantinos Giorspyros, Emmanuel Georgatis * $\mathbb{D}$, Anthoula Poulia and \\ Alexander E. Karantzalis * \\ Department of Materials Science and Engineering, University of Ioannina, 45100 Ioánnina, Greece; \\ ChristinaMathiou@hotmail.com (C.M.); kgiors64@gmail.com (K.G.); apoulia@cc.uoi.gr (A.P.) \\ * Correspondence: mgeorgat@uoi.gr (E.G.); akarantz@uoi.gr (A.E.K.)
}

Received: 17 June 2020; Accepted: 31 July 2020; Published: 5 August 2020

\begin{abstract}
A series of NiAl-Cr-Mo systems were produced and assessed as far as their microstructure and their sliding wear resistance is concerned. The NiAl content was kept constant and seven compositions of Cr-Mo were tested, namely, 40Cr-0Mo, 30Cr-10Mo, 25Cr-15Mo, 20Cr-20Mo, $15 \mathrm{Cr}-25 \mathrm{Mo}, 10 \mathrm{Cr}-30 \mathrm{Mo}$, and $0 \mathrm{Cr}-40 \mathrm{Mo}$. It was observed that most of the systems contained primary phases, eutectic microconstituents, and, occasionally, intermetallic phases as the outcome of peritectic reactions. The extent and the nature of all these microstructural features was proved to be affected by the $\mathrm{Cr} / \mathrm{Mo}$ relative ratio, and an attempt was conducted in order to explain the microstructural features based on solidification and other related phenomena. It was observed that the increase of the relative $\mathrm{Mo} / \mathrm{Cr}$ ratio led to a significant restriction/elimination of the eutectic microconstituent. The sliding wear response of the produced system seems to diverge from the classical sliding wear laws of Archard and is based on multiple factors such as the nature of the oxide phases being formed upon sliding, the nature and the extend of the intermetallic phases being formed upon solidification, and the integrity and rigidity of the primary phases-last to solidify areas interfacial region and the factors that may influence this integrity.
\end{abstract}

Keywords: high-entropy alloys; solidification; sliding wear

\section{Introduction}

During the last decades, NiAl-based alloys have been considered as potential candidates for high-temperature applications due to their enhanced properties at such extreme servicing conditions and possible substitutes for Ni-based superalloys [1]. However, the brittle nature of the NiAl intermetallic phase and their limited ductility, early enough, raised question on their possible modification so that their toughness and ductility can be improved. Towards this direction, research efforts were focused on the addition of refractory metals $(\mathrm{Cr}, \mathrm{Mo}$, Ta, etc.) within the NiAl matrix in order to overcome these drawbacks and their properties were, in most of the cases, evaluated in depth [2-6].

Within this frame, the addition of $\mathrm{Cr}$ within a NiAl intermetallic matrix has gained special scientific and research interest $[7,8]$. The potential substitution of Ni-based super-alloys, nevertheless, was not the only driving force for the development of NiAl-based system. The immergence of the new class of metallic materials, high-entropy alloys (HEAs), revealed another direction of the importance of the $\mathrm{Ni}$-Al-Cr elemental combinations. Indeed, a wide range of this novel material class has been based, developed, and assessed on the Ni-Al-Cr core [9-14]. This intensive research effort clearly showed the necessity and the importance of the in-depth understanding of the microstructural characteristics and mechanisms related to them and phenomena of the NiAl-Cr system. Fortunately, for the research 
community, Tang et al. [15] presented an exceptional research work where, based on thermodynamic and kinetic calculations, they showed a thorough approach on the possible microstructural configurations of the NiAl-Cr systems for various $\mathrm{Cr}$ compositions. Similar thermodynamic calculations of the $\mathrm{Ni}-\mathrm{Al}-\mathrm{Cr}$ system, with very important and useful results, were also performed by Duprin et al. [16].

In parallel with the works focused on the addition of $\mathrm{Cr}$ in NiAl matrix, Mo has also attracted significant research attention, and various works have been conducted concerning the development and microstructural property evaluation of NiAl-Mo systems with very promising results $[4,5,17,18]$.

By the development of HEAs point of view, a combination of $\mathrm{Cr}$ and Mo would be an interesting approach of gradually building medium to high-entropy systems. This combination of four elements (Ni-Al-Cr-Mo) has been examined in various research efforts. Chen et al. [19], for instance, studied the deformation and fracture behavior of directionally solidified NiAl-28Cr-6Mo eutectic alloy. They observed a eutectic lamellar microstructure with both the consisting phases being grown parallel and towards the same direction. The semicoherent nature of the eutectic constituent interface was responsible for the fracture behavior of this alloy. Whittenberger et al. [20] also examined a directionally solidified NiAl-31Cr-3Mo eutectic alloy and commented on the transition from lamellar to cellular configurations as a function of the growth rate. High-temperature compression tests did not reveal, in their work, any significant difference between the different eutectic patterns as far as the fracture toughness is concerned. Raj and Locci [21] proved that the different withdrawal rate significantly affects the microstructure of a eutectic NiAl-31Cr-3Mo alloy. Similar observations on the effect of solidification rates on the microstructure of Ni-33Al-33Cr-3Mo and Ni-33Al-31Cr-3Mo eutectic alloys were presented by Raj et al. [22]. Shang et al. [23] examined the microstructure and the room temperature fracture toughness of a directionally solidified $\mathrm{NiAl}-\mathrm{Cr}(\mathrm{Mo})$ alloys. They observed that the withdrawal rate, the temperature gradient, and the $\mathrm{Cr}$ composition are the main factors that affect the microstructural characteristics and the fracture toughness of the produced alloys. These indicative research efforts, provide a first hint on the importance of the NiAl-Cr-Mo alloy systems. Peng et al. [24] with their thermodynamic calculations through CALPHAD provided a thorough insight on the possible microstructural characteristics and morphology in the NiAl-Cr-Mo systems. Their theoretical predictions were also validated by their experimental results.

Despite the fact that the microstructure and the mechanical properties of NiAl-Cr-Mo systems were examined through various research efforts, limited work has been conducted so far on the sliding wear response of these systems. The most systematic approach on this issue has been conducted by Guo and his colleagues [25] who examined the sliding wear response of various NiAl-Cr-Mo-based systems with and/or without the presence of other externally introduced reinforcing phases. However, this specific field is open for further experimental and research investigations.

The present work is part of a wider research effort to design and develop new high-entropy alloys around the fundamental core of the NiAl-Cr system. The authors have, at a first instance, investigated the basic NiAl-Cr core system, as far as the microstructural features and the related mechanisms are related, along with the alterations that small additions of Mo may cause [26]. In the present work, higher Mo additions (up to 40 at.\%, no Cr) were selected maintaining, however, a constant Cr-Mo addition of 40 at.\%. This compositional range was selected in order to examine the influence of the $\mathrm{Cr} / \mathrm{Mo}$ ratio on both the microstructural features and the sliding wear response of the produced alloys. The objective of this approach is to establish compositional ranges of Ni-Al-Cr-Mo for optimum medium entropy alloy. The primary target was to establish microstructural morphologies where the eutectic microconstituent is significantly eliminated and if possible vanished. Vanishing of the eutectic phase will lead to simple microstructures that may permit more flexible and precise control of the system properties. This will permit the transition to the next level of next elemental addition (primary work on $\mathrm{W}$ additions has already been undertaken), in order to develop new high-entropy alloys of simple microstructures. 


\section{Experimental Procedure}

High-purity elemental powders were mixed in the intended atomic ratio in order to produce various Ni-Al-Cr-Mo alloys. Approximately, $5 \mathrm{~g}$ of raw materials, with purities higher than $99.5 \%$, were subjected to uniaxial compression in order to make green pellets with targeted (nominal) composition according to Table 1 . The produced green pellets were arc melted at least 5 times in order to ensure that all raw materials were well mixed in liquid prior to solidification. The samples were flipped for each melting cycle in order to improve chemical homogeneity. The arc current was kept constant at $120 \mathrm{~A}$ in all melting and remelting steps. The melting was performed on a water cooled copper-based mold. Cooling conditions associated with the final microstructure are also mentioned in other experimental efforts $[27,28]$. The actual composition was checked using EDS mapping in the SEM in at least 3 different locations of lower magnification and all fell within the measured compositions presented in Table 1.

Table 1. Nominal, actual, and individual phases compositions after EDS point and mapping analysis. Elemental ratios of interest are also included.

\begin{tabular}{|c|c|c|c|c|c|c|c|c|c|c|}
\hline System & $\begin{array}{c}\text { Composition } \\
\text { (at.\%) }\end{array}$ & Al & $\mathrm{Ni}$ & $\mathrm{Cr}$ & Mo & $\mathrm{Mo} / \mathrm{Cr}+\mathrm{Mo}$ & $\mathrm{Mo} / \mathrm{Ni}+\mathrm{Mo}$ & Mo/Al + Mo & $\mathrm{Cr} / \mathrm{NiAl}+\mathrm{Cr}$ & $\delta$ \\
\hline \multirow{5}{*}{$\begin{array}{l}\text { Alloy A: } \\
\text { AlNi-40Cr }\end{array}$} & Nominal & 30 & 30 & 40 & 0 & 0 & 0 & 0 & $57 / 100$ & \multirow{5}{*}{4.96} \\
\hline & Actual & 26.21 & 33 & 40.76 & 0 & 0 & 0 & 0 & 0 & \\
\hline & Primary Dark & 11.88 & 10.70 & 77.42 & 0 & 0 & 0 & 0 & $87.5 / 100$ & \\
\hline & Primary Light & 35.02 & 46.34 & 18.65 & 0 & 0 & 0 & 0 & $32 / 100$ & \\
\hline & Eutectic Overall & 36.92 & 43.76 & 19.32 & 0 & 0 & 0 & 0 & $32 / 100$ & \\
\hline \multirow{5}{*}{$\begin{array}{c}\text { Alloy B: } \\
\text { AlNi-30Cr-10Mo }\end{array}$} & Nominal & 30 & 30 & 30 & 10 & $25 / 100$ & $25 / 100$ & $25 / 100$ & $50 / 100$ & \multirow{5}{*}{4.83} \\
\hline & Actual & 25.7 & 33.2 & 30.99 & 10.11 & $25.5 / 100$ & $23 / 100$ & $28 / 100$ & $52 / 100$ & \\
\hline & Primary Light & 8.09 & 7.01 & 58.98 & 25.91 & $30.5 / 100$ & $78 / 100$ & $76 / 100$ & $88 / 100$ & \\
\hline & Primary Halo & 14.77 & 12.9 & 53.26 & 19.07 & $24 / 100$ & $60 / 100$ & $56 / 100$ & $80 / 100$ & \\
\hline & Eutectic Overall & 39.47 & 47.83 & 10.77 & 1.92 & $15 / 100$ & $4 / 100$ & $4.5 / 100$ & $20 / 100$ & \\
\hline \multirow{6}{*}{$\begin{array}{c}\text { Alloy C: } \\
\text { AlNi-25Cr-15Mo }\end{array}$} & Nominal & 30 & 30 & 25 & 15 & $37.5 / 100$ & $33 / 100$ & $33 / 100$ & $45 / 100$ & \multirow{6}{*}{4.87} \\
\hline & Actual & 23.74 & 33.96 & 25.99 & 16.31 & $39 / 100$ & $32 / 100$ & $41 / 100$ & $47 / 100$ & \\
\hline & Primary Light & 9.54 & 6.47 & 39.48 & 44.52 & $53 / 100$ & $87 / 100$ & $82 / 100$ & $83 / 100$ & \\
\hline & Primary Halo & 14.72 & 19.38 & 45.05 & 20.85 & $32 / 100$ & $52 / 100$ & $58 / 100$ & $73 / 100$ & \\
\hline & Eutectic Overall & 29.26 & 39.06 & 21.66 & 10.01 & $32 / 100$ & $20 / 100$ & $26 / 100$ & $39 / 100$ & \\
\hline & Dark Phase & 37.01 & 52.16 & 9.40 & 1.42 & $13 / 100$ & $3 / 100$ & $4 / 100$ & $18 / 100$ & \\
\hline \multirow{6}{*}{$\begin{array}{c}\text { Alloy D: } \\
\text { AlNi-20Cr-20Mo }\end{array}$} & Nominal & 30 & 30 & 20 & 20 & $50 / 100$ & $40 / 100$ & $40 / 100$ & $40 / 100$ & \multirow{6}{*}{4.33} \\
\hline & Actual & 23.88 & 35.10 & 19.43 & 21.59 & $53 / 100$ & $38 / 100$ & $47.5 / 100$ & $40 / 100$ & \\
\hline & Primary Light & 8.04 & 4.83 & 24.09 & 63.04 & $72 / 100$ & $93 / 100$ & $89 / 100$ & $75 / 100$ & \\
\hline & Primary Halo & 6.13 & 7.93 & 54.28 & 31.65 & $37 / 100$ & $20 / 100$ & $16 / 100$ & $88 / 100$ & \\
\hline & Eutectic Overall & 29.03 & 41.11 & 17.36 & 12.50 & $42 / 100$ & $23 / 100$ & $30 / 100$ & $33 / 100$ & \\
\hline & Dark Phase & 37.51 & 54.84 & 6.98 & 0.67 & $9 / 100$ & $1 / 100$ & $2 / 100$ & $13 / 100$ & \\
\hline \multirow{6}{*}{$\begin{array}{c}\text { Alloy E: } \\
\text { AlNi-15Cr-25Mo }\end{array}$} & Nominal & 30 & 30 & 15 & 25 & $62.5 / 100$ & $46 / 100$ & $46 / 100$ & $33 / 100$ & \multirow{6}{*}{4.04} \\
\hline & Actual & 23.44 & 34.70 & 14.82 & 27.03 & $65 / 100$ & $44 / 100$ & $54 / 100$ & $34 / 100$ & \\
\hline & Primary Light & 7.3 & 3.58 & 21.91 & 67.11 & $75 / 100$ & $95 / 100$ & $90 / 100$ & $80 / 100$ & \\
\hline & Primary Halo & 5.20 & 7.92 & 53.40 & 33.48 & $39 / 100$ & $81 / 100$ & $87 / 100$ & $86 / 100$ & \\
\hline & Eutectic Overall & 28.77 & 41.58 & 15.82 & 13.83 & $47 / 100$ & $25 / 100$ & $33 / 100$ & $31 / 100$ & \\
\hline & Dark Phase & 39.53 & 53.70 & 6.07 & 0.70 & $10 / 100$ & $1 / 100$ & $2 / 100$ & $12 / 100$ & \\
\hline \multirow{6}{*}{$\begin{array}{c}\text { Alloy F: } \\
\text { AlNi-10Cr-30Mo }\end{array}$} & Nominal & 30 & 30 & 10 & 30 & $75 / 100$ & $50 / 100$ & $50 / 100$ & $25 / 100$ & \multirow{6}{*}{3.63} \\
\hline & Actual & 23.71 & 35.51 & 10.06 & 30.73 & $75 / 100$ & $46 / 100$ & $56 / 100$ & $25 / 100$ & \\
\hline & Primary Light & 6.32 & 3.45 & 15.45 & 74.79 & $83 / 100$ & $94 / 100$ & $92 / 100$ & $76 / 100$ & \\
\hline & Peritectic Halo & & & & & Difficult to A & certain & & & \\
\hline & Eutectic Overall & 33.99 & 47.46 & 7.33 & 11.82 & $62 / 100$ & $20 / 100$ & $26 / 100$ & $15 / 100$ & \\
\hline & Dark Phase & 41.59 & 53.94 & 3.86 & 0.62 & $14 / 100$ & $1 / 100$ & $1.5 / 100$ & $7.5 / 100$ & \\
\hline \multirow{5}{*}{$\begin{array}{l}\text { Alloy G: } \\
\text { AlNi-40Mo }\end{array}$} & Nominal & 30 & 30 & 0 & 40 & 100 & $57 / 100$ & $57 / 100$ & 0 & \multirow{5}{*}{1.96} \\
\hline & Actual & 23.06 & 37.30 & 0 & 39.65 & 100 & $52 / 100$ & $63 / 100$ & - & \\
\hline & Primary Light & 6.91 & 3.11 & 0 & 89.98 & 100 & $97 / 100$ & $93 / 100$ & - & \\
\hline & Eutectic Overall & 35.62 & 55.51 & 0 & 8.87 & - & $14 / 100$ & $20 / 100$ & $16 / 100$ & \\
\hline & Dark Phase & 41.13 & 57.94 & 0 & 0.96 & 100 & $1.5 / 100$ & $2 / 100$ & $2 / 100$ & \\
\hline
\end{tabular}

The microstructure of the alloys was studied in their as-cast condition. The metallographic specimens were mounted in Bakelite, abraded on SiC papers up to 2400 grit, and then polished with a $3 \mu \mathrm{m}$ diamond suspension. The polished specimens were etched using aqua regia. Alloy's microstructure was analyzed with the use of a scanning electron microscope (SEM) (JEOL 6510 LV, Tokyo, Japan) equipped with both backscatter electron (BSE) and energy-dispersive spectroscopy (EDS) detector of X-Act type by Oxford Instruments (Oxford, UK). X-ray diffraction (XRD) patterns were obtained using a D8 ADVANCE diffractometer (Bruker AXS GmbH, MA, USA), operating with $\mathrm{CuK}_{\alpha}$ radiation $(\lambda=1.5406 \AA)$ and a secondary beam graphite monochromator. Samples were scanned over 
an angular $2 \theta$ range from $20^{\circ}$ to $120^{\circ}$, in steps of $0.02^{\circ}(2 \theta)$ at a rate of $2 \mathrm{~s}$ per step (overall run duration $10,000 \mathrm{~s})$.

Vickers microhardness $\left(\mathrm{HV}_{1}\right)$ was measured using a $136^{\circ}$ diamond pyramid for $5 \mathrm{~s}$ of load $(1 \mathrm{~kg})$ application. Sliding wear tests were performed using a ball-on-disk apparatus (CSM Instruments, Zurich, Switzerland) at ambient temperatures with relative humidity around $70 \%$. The externally applied load was $5 \mathrm{~N}$. The overall sliding distance was $1000 \mathrm{~m}$, and the sliding speed was $10 \mathrm{~cm} / \mathrm{s}$. A 100Cr6, $6 \mathrm{~mm}$ steel ball was used as a counter body material. All specimens were acetone cleaned and their weight was measured. Tests were interrupted every $200 \mathrm{~m}$, and the specimens were reweighted. Wear tracks were examined by SEM-EDS analysis. Three independent runs were carried out for each individual alloy system.

\section{Results and Discussion}

\subsection{Parametric Model Initial Predictions}

A detailed analysis of the parametric models for the prediction of the microstructural features of HEAs is given in Appendix A.

Table 2 presents the various calculated parameters for the different parametric models for both the nominal and the actual compositions of the produced systems. It is important at this stage to comment on the predictions of these models. According to the Zhang et al. [29] parametric model, the values of parameter $\delta$ are below 8.5 , which is the proposed upper limit, and so are the $\Delta \mathrm{H}_{\text {mix }}$ values. On the contrary, half of the systems show values of $\Delta S_{\text {mix }}$ outside the range proposed for single-phase solid solution (30Cr-10Mo, $10 \mathrm{Cr}-30 \mathrm{Mo}, 0 \mathrm{Cr}-40 \mathrm{Mo}, 40 \mathrm{Cr}-0 \mathrm{Mo}$, respectively), which is a strong indication for potential phase segregation in their case. In the case of the geometric factor $\gamma$ proposed by Wang et al. [30], all systems show values below 1.175, which is the upper acceptable limit. In the King et al. [31] model on the other hand, despite the fact that it provides values of the $\delta$ parameter within the accepted ranges, the parameter $\Phi$ is, in all cases, significantly lower than the value 1.0, which is the lowest acceptable limit, and as such, strong tendency for phases segregation for all systems is expected. For the Yang and Zhang [32] model, values of $\delta$ and $\Omega$ are within the accepted limits, with the exemption of alloy $(0 \mathrm{Cr}-40 \mathrm{Mo})$, where $\Omega$ is less than 1.1 proposed by the model as the lower limit. One of the most important models, which is especially related to the present effort, is the model of Troparevksy et al. [33] that deals especially with the thermodynamic tendency for intermetallic phase formation. As in the present work, the NiAl intermetallic phase is one of the major constituents of the produced alloys, the predictions of the Troparevksy el al. [33] model gains extra importance. As such, the model predicts the inevitable formation of $\mathrm{NiAl}$ intermetallic phase since it possesses an extremely low $\Delta \mathrm{H}$ of formation value ( $-677 \mathrm{meV} /$ atom), which is by far outside the proposed $-232 \mathrm{meV} /$ atom $<\Delta \mathrm{H}_{\mathrm{f}}<37 \mathrm{meV} /$ atom range for single-phase stability. Finally, the model of Senkov et al. [34], which also pays special attention on the formation of intermetallic phases, clearly depicts that the formation of intermetallic phase ( $\mathrm{NiAl}$ in the present case) is strongly expected. 
Table 2. The values of the important parameters for the parametric models used in order to predict the formation of not of single solid solution phases.

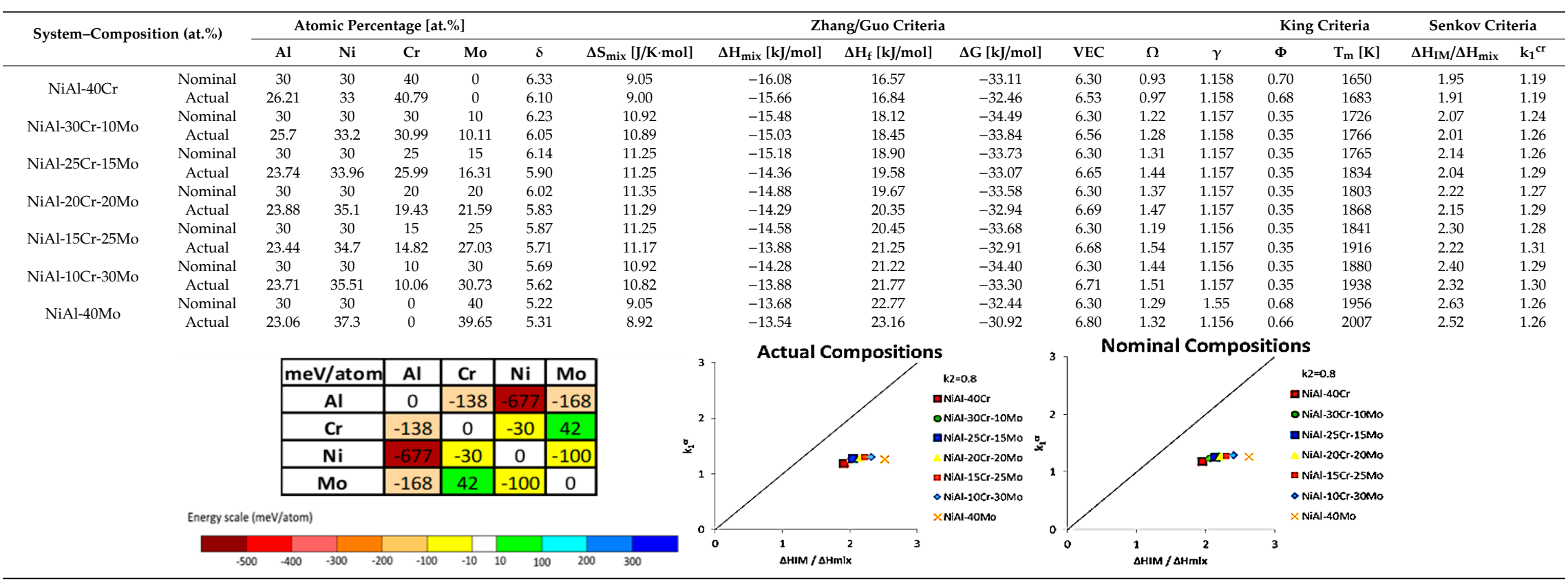


A possible concluding remark, as the parametric model predictions are concerned, is the fact that there is no consistent tendency for either a single-phase solid solution or multiple-phase formation. The actual microstructures do verify the presence of multiple phases, as it will be discussed in the following paragraph. This skepticism on the parametric model prediction validity, which has been expressed by many researchers (Pickering et al. [35], Karantzalis et al. [36-38]), should, however, by no means reduce their importance as they do comprise powerful tools in the process of designing new alloys and systems of controllable microstructures.

\subsection{Microstructural Features}

Figure 1a-g presents the microstructures of the different alloys produced in the present effort, and Table 1 provides the EDS point analysis data associated with the different phases being present in each individual alloy. More specifically, according to Figure 1a, alloy A consists of primary dendrites and a eutectic microconstituent. It is also evident that the eutectic constituent morphology varies from a central (hive-like) configuration to a more lamellar-like structure towards the outer regions, close to the primary dendrites. EDS analysis (Table 1) shows that the primary dendritic phases are rich in $\mathrm{Cr}$, whereas, within the eutectic phase, the light areas are rich in $\mathrm{Cr}$ and the dark phases are rich in $\mathrm{Ni}$ and Al.

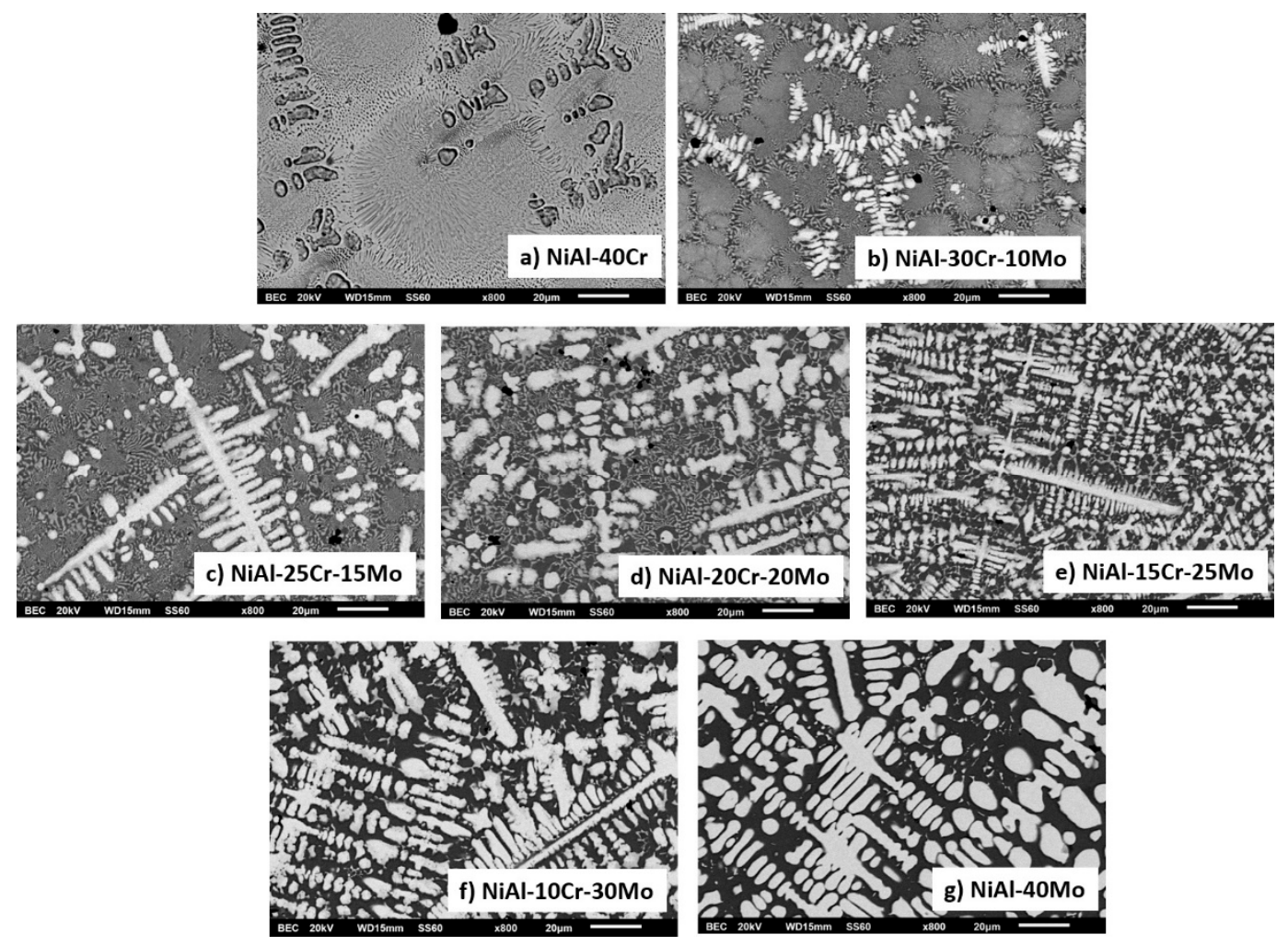

Figure 1. SEM images showing a panoramic view of the different systems produced in the present effort: (a) NiAl-40Cr alloy showing primary phases and eutectic areas of multiple morphologies, (b) NiAl-30Cr-10Mo alloy showing primary phases and eutectic microconstituent. Perimetric to the primary grains halo zones can be spotted, (c) NiAl-25Cr-15Mo alloy consisting of primary phase, halo zones, and eutectic phases, (d) NiAl-20Cr-20Mo alloy with a first primary phase surrounding by halo zones, traces of second primary phase, and eutectic microconstituent, (e) NiAl-15Cr-25Mo alloy showing a first primary phase with perimetric halo zones, a second primary phase, and a eutectic phase significantly restricted, (f) NiAl-10Cr-25Mo consisting mostly of two primary phases. The eutectic areas are difficult to be distinguished. (g) NiAl-40Mo consisting of two primary phases and limited eutectic areas. 
Alloy B, according to Figure $1 \mathrm{~b}$, consists of a primary dendritic phase and a eutectic microconstituent. A gray phase parametrically of the primary dendrites can be distinguished. Based on the data of Table 1, the primary dendritic phase is rich mainly in $\mathrm{Cr}$ followed by Mo, with some Ni and Al being dissolved, whereas the dark phase of the eutectic area is mainly enriched in $\mathrm{Ni}$ and Al. The perimetric dendritic halo is rich in Mo and Ni. The eutectic phases seem to follow an almost typical lamellar eutectic growing mode varying from more refined configurations at the core of the eutectic areas, towards coarser modifications at the periphery of the eutectic regions, close to the interface with the primary dendritic phase boundaries.

By increasing the Mo content (alloy C), the microstructure is lightly modified by means that the eutectic phase is reduced and the dark interdendritic phase is expanded. EDS analysis reveals that inside the core of the primary dendrites, the Mo content is increased and the $\mathrm{Cr}$ content is decreased. The dendritic halo is rich in $\mathrm{Ni}$, as in the previous case, and the dark phase is rich in $\mathrm{Ni}$ and $\mathrm{Al}$. Despite the reduction of the eutectic area, its morphology is still of typical lamellar configuration.

According to Figure 1d (alloy D), further increase of the Mo content leads to further distinguished microstructural alterations. The primary dendrites persist to exist, yet the halo areas are more expanded. The dark phase areas are also increased and the eutectic areas are severely constrained, and, wherever present, their morphology starts to fade from the typical lamellar configuration. EDS analysis shows that the Mo content is significantly increased within the primary dendrite cores and the dendrite halos, whereas the dark areas are still rich in $\mathrm{Ni}$ and $\mathrm{Al}$, practically unchanged compared to the previous cases.

In the case of alloy E, where the Mo content reaches the values of 25 at. $\%$, the microstructure is further modified. The extent of the peripheral halos is increased as the extent of the dark phase also does. It is worth noticing, however, that the eutectic morphology is almost eliminated. Table 1 data show that the content of the primary dendrite cores and the halo areas is further increased, whereas the dark areas are constantly rich in $\mathrm{Ni}$ and $\mathrm{Al}$.

Further increase of the Mo content, alloy F in Figure 1f, does not seem to considerably alter the morphological features, compared to the previous case.

Alloy G (no Cr addition), Figure 1g, appears to consist of two phases: a light phase rich in Mo and a dark phase rich in $\mathrm{Ni}$ and $\mathrm{Al}$. However, limited areas of eutectic microconstituent can also be observed.

Apart from the various EDS analysis, XRD measurements complement the characterization of the various phases being formed in the examined alloys (Figure 2). It can be observed that the NiAl-40Cr alloy consists basically of two BCC phases, those of $\mathrm{NiAl}(\mathrm{B} 2)$ and $\mathrm{Cr}$ (A2), as expected. The introduction of Mo leads to the formation of two intermetallic phases ( $\mathrm{AlMo}_{3}$ and $\left.\mathrm{MoNi}\right) . \mathrm{AlMo}_{3}$ seems to vanish for high Mo additions (over 20\%Mo), whereas MoNi persists for even higher Mo concentrations. The NiAl-40 Mo alloy contains practically Mo and NiAl phases. Another important observation is the fact that from alloy A to alloy $\mathrm{G}$, there is a gradual shift of one of the BCC phases, that of $\mathrm{Cr}$, from $\mathrm{Cr}$ in the case of alloy A to Mo in the case of alloy G, a fact that is also expected. Despite the fact that TEM examination could provide more details on the peritectic halos formation, such examination, as adopted in other experimental efforts $[27,28]$, was not adopted since the SEM analysis provides a significant hint of the peritectic reaction progress.

The first important observation to be noticed is the fact that the microstructural features of each individual alloy system produced in the present effort and presented in Figure 1, are in agreement with the calculated partial liquidus surface of the NiAl-Cr-Mo system proposed by Peng et al. [24] and presented graphically reconstructed in Figure 3, especially as far as the eutectic phase presence and extend in concerned. According to Figure 3, as the Mo content increases, the overall system composition continuously diverges away from the eutectic liquidus line and, as such, the tendency of eutectic constituent formation gradually diminishes. Indeed, as the alloy microstructure show, in alloys with 20, 25, and 30 at.\% Mo, respectively, the significant reduction of the eutectic regions becomes profound, which, at last, are practically vanished in the 40 at.\% Mo system. On the other hand, as the Cr content increases (alloys with 25, 30, and 40 at.\% Cr), the system compositions converge towards 
the eutectic liquidus line, and as such, the eutectic regions should gradually increase and dominate, a fact that is clearly verified by the obtained microstructures of these systems in the present effort. It has to be mentioned, however, that this is a general speculation on the microstructural features and that more detailed approach on the various phases formed in each case will be presented in a following paragraph.

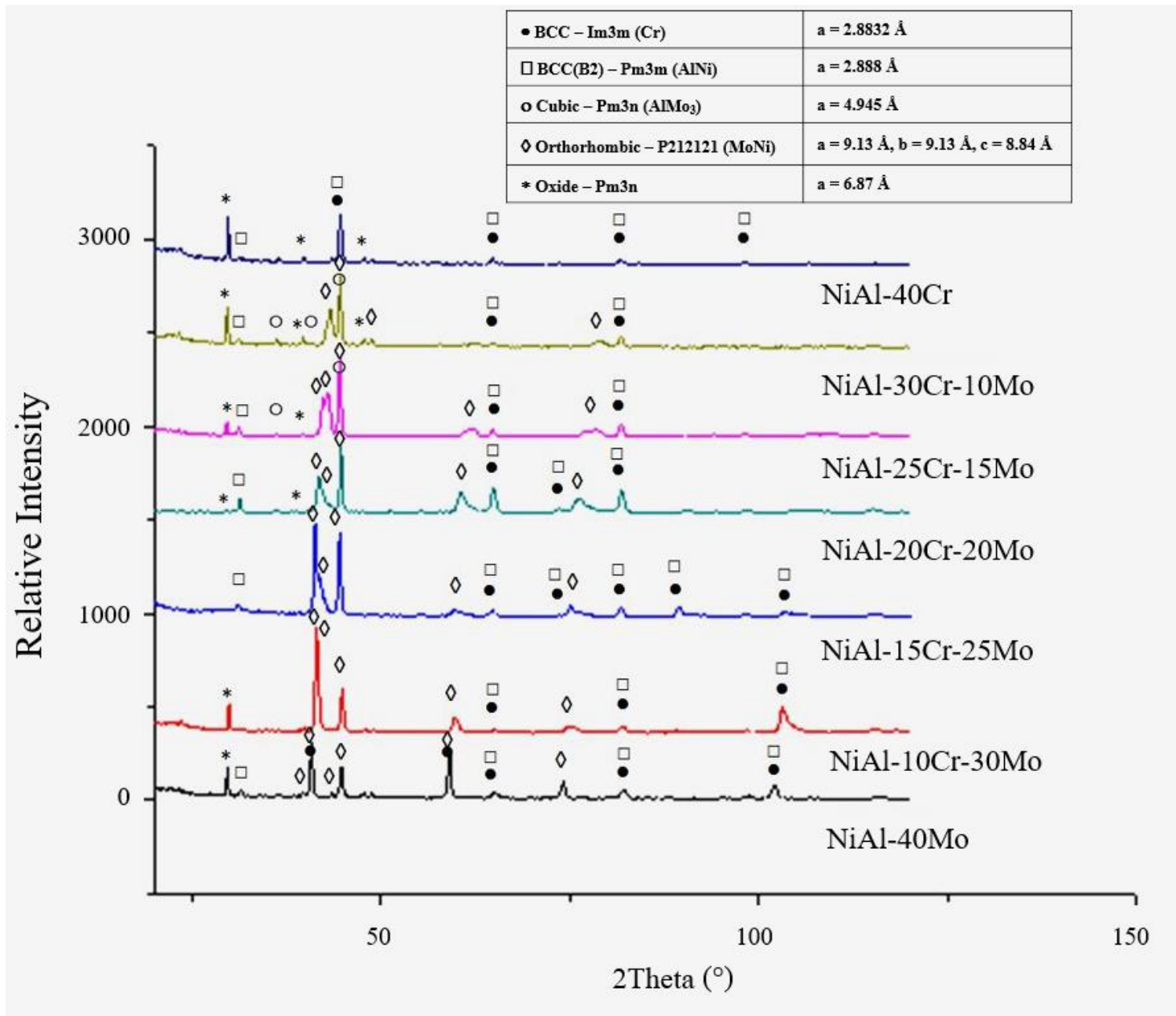

Figure 2. XRD graph showing the evolution of the phases with altering Mo content. Alloy A consists of two BCC phases, alloys B, C, and D also contain two BCC structures along with two intermetallic phases, alloy E and F contain two BCC structures and one intermetallic phase, and alloy G contain two BCC structures. 


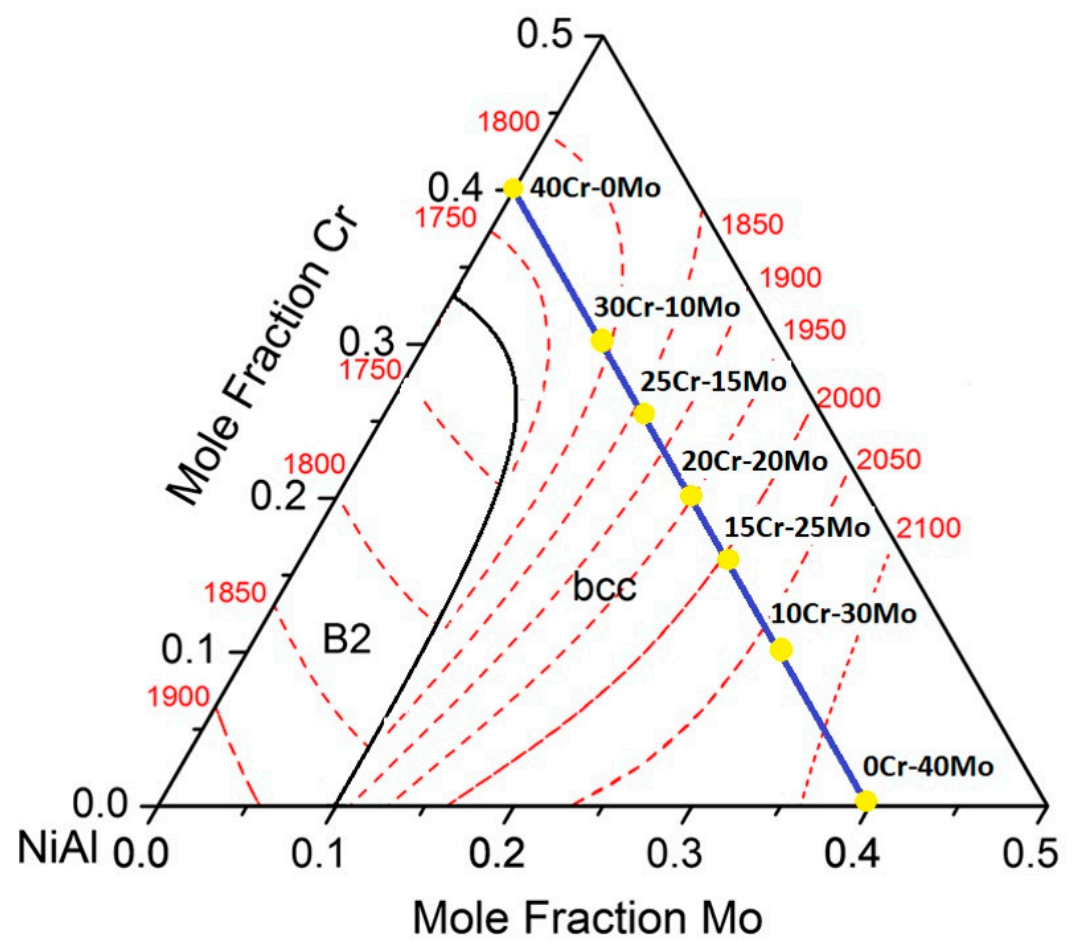

Figure 3. Graphical reconstruction of the ternary NiAl-Mo-Cr system as proposed by Peng et al. [24]. The blue line and the yellow spots indicate the composition of the system produced in the present effort.

\subsection{Solidification and Phase Formation Considerations}

It was shown in Section 3.2 that in overall, the microstructures of the produced systems follow the trends and the predictions of the work of Peng et al. [24]. It is important, nevertheless, to examine in more details, the various phases formed in each individual alloy and to formulate a potential solidification and microstructural evolution sequence.

\subsubsection{Alloy A:NiAl-40Cr}

Since this alloy contains no Mo, an approach to explain the various microstructural features should be passed on the partial binary eutectic system. As such, according to the NiAl-Cr pseudobinary phase diagram proposed by Tang et al. [15] and Duprin et al. [16], this composition corresponds to a hypereutectic alloy, which subsequently means that its microstructure should consist of the primary A2 (Cr) phase and a eutectic microconstituent. Interestingly, the microstructure seems to follow this general pattern, however, two phases seem to grow primarily and prior to the eutectic constituent: a dark phase and a light phase that either grows peripherically to the dark phase or as an interdendritic phase. A line scan EDS analysis (Figure 4) from the center of the dark phase and outwards reveals that the dark core is rich in $\mathrm{Cr}$ (an A2 phase), whereas the light phase is rich in $\mathrm{Ni}$ and $\mathrm{Al}$ (a B2 phase). In order to explain this sequence of events other factors such as recalescence and undercooling should be taken into consideration. According to the predictions of Tang et al. [15], two important temperatures can play vital role in the final phase formation: the T0-B2 and T0-A2 temperatures. T0-A2 and T0-B2, according to Tang et al. [15] and Laughlin and Hono [39], are defined as the maximum temperature at the interface, where partitionless (a limited case where the concentration of the solid is equal to the concentration of liquid at the interface) solidification can occur. For this specific composition (40 at.\% Cr), Tang et al. [15] show that T0-B2 is considerably higher than the T0-A2 one. The resulted microstructure shows, hence, that the expressed-at the initial solidification stages-undercooling falls below the T0-A2 phase, and as such, the A2 phase starts to nucleate and grow in a partitionless mode. As soon as a critical mass of $\mathrm{A} 2$ is formed, recalescence and subsequent heat release raises the temperature above the T0-A2 phase and below the T0-B2 phase, establishing conditions for the development of growth of the B2 phase as a 
second stage. Practically, the expressed undercooling established conditions of the so-called decoupled growth leading to a sequential development and growth of A2 and B2 phases in a partitionless mode. Similar phenomena of decoupled growth have also been reported in other experimental efforts dealing with regular and anomalous eutectic solidification [40-46]. It is also important to notice, based on EDS data of Table 1, that the Cr dissolution within this primary B2 phase is at contents higher than those predicted by the pseudobinary eutectic NiAl-Cr phase diagram proposed by Tang et al. [15] and Duprin et al. [16]. These higher Cr contents are a strong indication of a more intensive solute trapping effect.
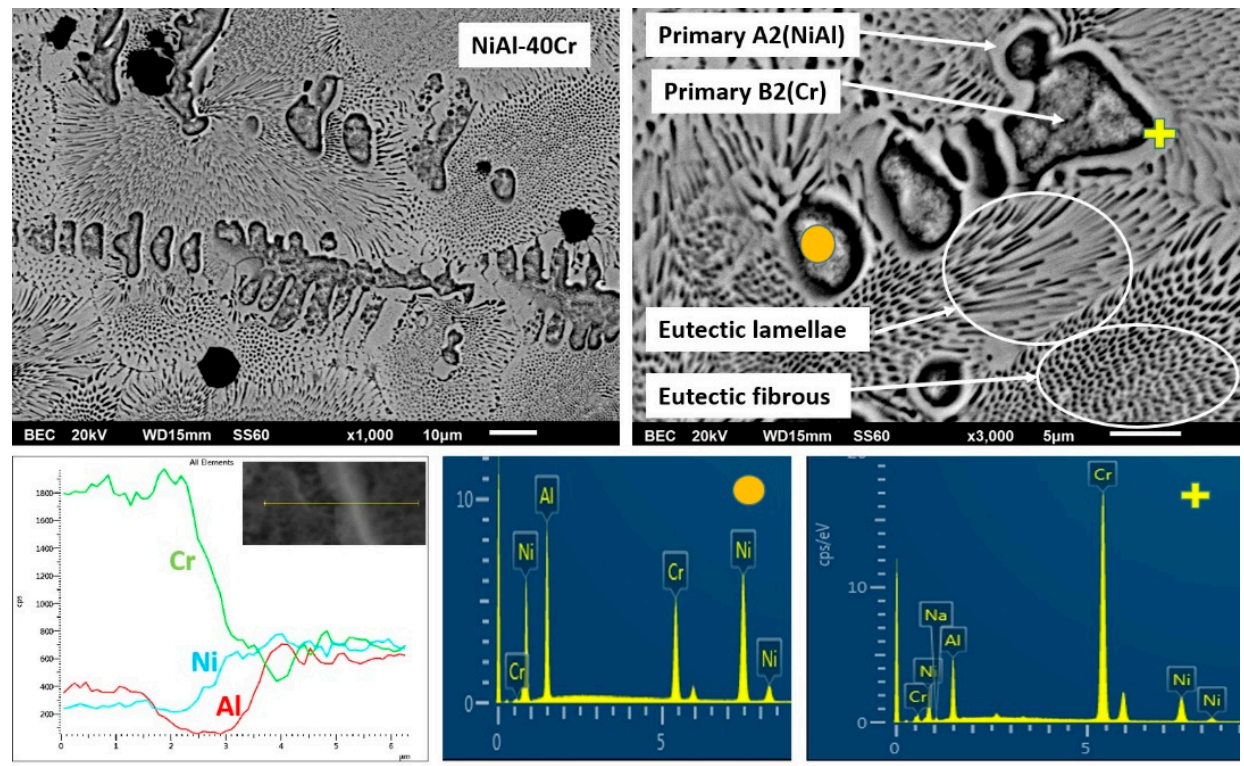

Figure 4. Higher magnification SEM images showing the microstructure of alloy A (NiAl-40Cr). Line scan EDS analysis and point EDS analysis are also included.

Once the primary B2 is formed, further heat release due to recalescence causes temperature increase at the surrounding liquid above T0-B2, establishing conditions for eutectic undercooling, leading to the formation and growth of eutectic microconstituent. The alterations of the eutectic morphology observed in this system are also attributed to recalescence phenomena: As soon as temperature rises above the T0-B2 point, the undercooling for eutectic growth is considerably high. High undercooling favors rod- or hive-like (commonly referred as fibrous) eutectic morphologies [47]. Taking into consideration the postulates of Li and Kuribayashi [47], according to which the eutectic constituent commences at the central areas of the remaining liquid, the hive-like eutectic morphology observed in the central areas of the remaining liquid observed in the present effort are, hence, expected. As the initial eutectic phases grow radially, recalescence causes further increase of the remaining liquid temperature, a fact that establishes conditions of lower growth kinetics and more intensive interphase diffusion, leading to more lamellar (regular) eutectic configurations.

\subsubsection{Alloy B: NiAl-30Cr-10Mo}

It has been already mentioned in a previous paragraph that the overall microstructure complies with the predictions suggested by Peng et al. [24] according to which a primary phase and a eutectic constituent are expected to form. However, a detailed examination, especially of the primary phase, reveals great differences compared to the analogous primary phase in the previous alloy (Figure 5). EDS analysis (Table 1) indicates that the primary phase is rich in $\mathrm{Cr}$ and Mo with small amounts of $\mathrm{Ni}$ and $\mathrm{Al}$ being dissolved. It seems, therefore, that the substitution of $10 \% \mathrm{Cr}$ by Mo stabilizes the A2 phase as the primary phase. 

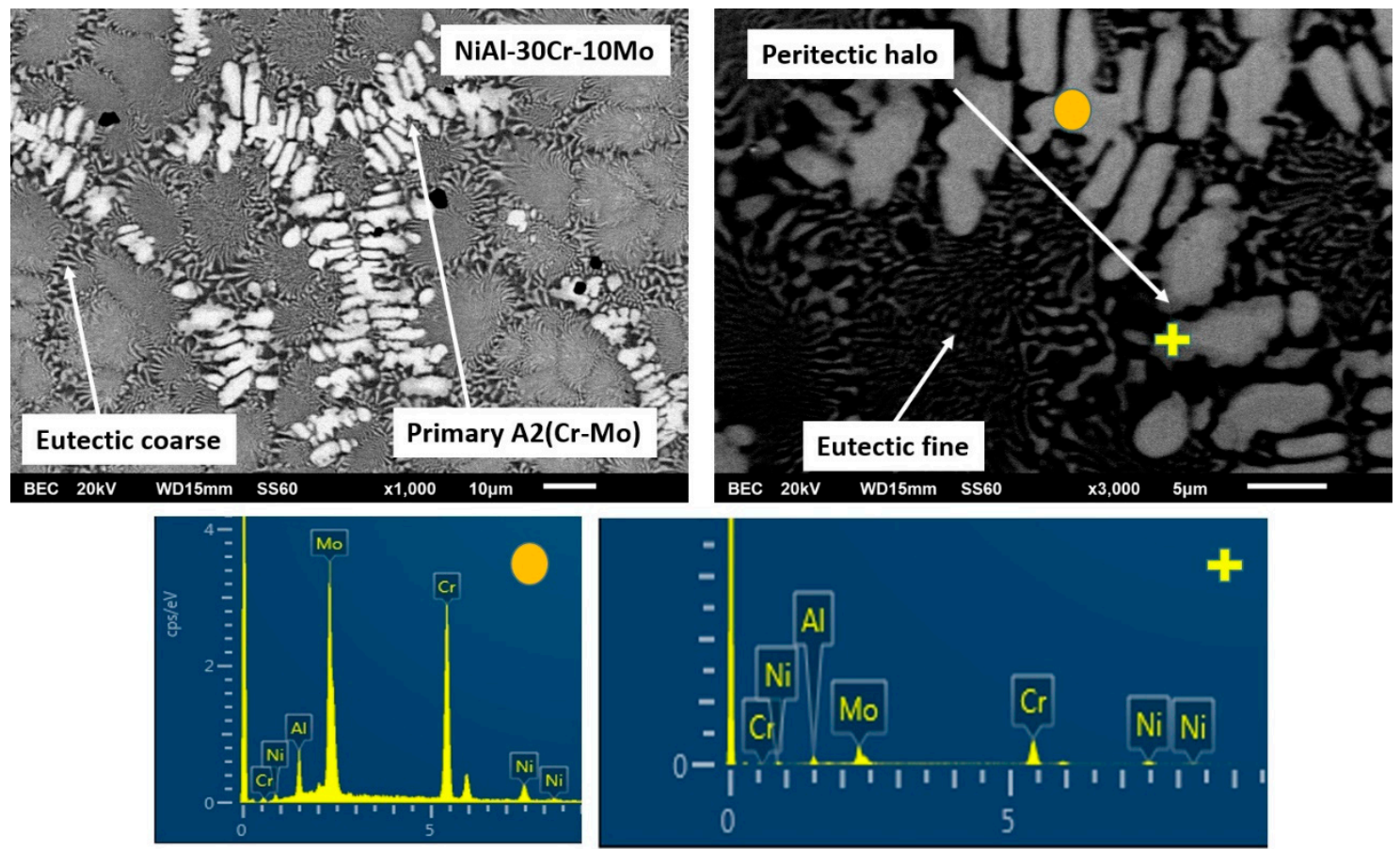

Figure 5. SEM images of magnification presenting the microstructural features of alloy B (NiAl-30Cr-10Mo). EDS point analysis on selective areas are also included.

This A2 primary phase stabilization can be explained by the following phenomena that can act either individually of synergistically:

(1) Based on EDS analysis (Table 1), the primary A2 phase contains $\mathrm{Cr}$ and Mo in relative ratio of $\mathrm{Cr} / \mathrm{Mo} \approx 70 / 30$. According to the $\mathrm{Cr}$-Mo phase diagram [48], this ratio leads to an increase of the liquidus temperature by several degrees compared to the melting point of $\mathrm{Cr}$. This observation, in conjunction with the fact that Cr-Mo show complete solubility, leads to the fact that the presence of Mo controls the initiation of the solidification process, binds $\mathrm{Cr}$ form the liquid phase, and forms a primary modified $\mathrm{A} 2 \mathrm{Cr}$ phase rich in Mo. It is worth noticing, as well, that if the value of the melting temperature of the primary phase, as calculated by the parametric models $(\sim 2200 \mathrm{~K})$, is taken into consideration, the tendency for the primary $\mathrm{Cr}(\mathrm{Mo})$ formation becomes even stronger.

(2) The presence of Mo most likely affects the T0-A2 temperature presented by Tang et al. [15]. The presence of Mo, as stated previously, raises considerably the liquidus temperature. Having taken into consideration the fact that during arc melting, the temperature of heating and melting of the various systems was kept constant (arc parameters were not modified or changed), it is logical to assume that the increase of the liquidus temperature corresponds to a lower degree of liquid phase overheating, compared with the case of the NiAl-40Cr alloy. A lower degree of liquid phase overheating, as Mei and Li [49] and Yang et al. [50] postulate, leads to a reduction of the necessary for nucleation undercooling. In the case of the present work, this practically implies that the presence of Mo shifts the T0-A2 temperatures towards higher values, i.e., the necessary undercooling for primary $\mathrm{Cr}(\mathrm{Mo}) \mathrm{A} 2$ phase nucleation is reduced. It is strongly likely, that the established upon the initial stages of solidification, undercooling conditions were dropped below the affected $\mathrm{T} 0-\mathrm{A} 2 \mathrm{Cr}(\mathrm{Mo})$ values, and as such, the formation of A2 $\mathrm{Cr}(\mathrm{Mo})$ phase became dominant.

(3) Synergistically to these potential mechanisms, another parameter that may also enhance the stability of the primary $\mathrm{A} 2 \mathrm{Cr}(\mathrm{Mo})$ phase is the lattice distortion value $\delta$. As shown in Table 1 , the calculated lattice distortion $\delta$ in the case of the primary NiAl B2 in alloy NiAl-40Cr is 
roughly 6.8 , whereas in the case of the primary $\mathrm{A} 2 \mathrm{Cr}(\mathrm{Mo})$ in the present system, $\delta$ is roughly 4.8. This difference makes the $\mathrm{A} 2 \mathrm{Cr}(\mathrm{Mo})$ phase more favorable both in stability and kinetics of formation.

These potential phenomena can explain the formation of the core of A2 primary phase. However, as indicated in Figure 1b, a halo structure perimetrically to the basic $\mathrm{Cr}(\mathrm{Mo})$ core is observed. This type of perimetric phase formation around a primary phase in the case of alloy structures, very often, indicates the expression of a peritectic reaction. EDS analysis (Figure 5 and Table 1) indicates a sharp increase of $\mathrm{Al}$ and $\mathrm{Ni}$ content within the halo areas. A thorough investigation of the binary phase diagrams of the elements related to this system, surprisingly, revealed the presence of peritectic reaction in the case of Mo-Ni phase diagram around $1640 \mathrm{~K}$ [51] and in the case of Mo-Al phase diagram, at roughly $2330 \mathrm{~K}$ [52]. For the Mo-Al peritectic reaction to occur, an $\mathrm{Al}$ dissolution within Mo, a 20 at.\% $\mathrm{Al}$ concentration should be exceeded. The EDS analysis of the primary phase reveals a relative $\mathrm{Mo} / \mathrm{Al}$ ratio of roughly 74/24. Under these circumstances, it is possible that a first peritectic reaction at these temperature ranges can occur, leading to the formation of a first zone of peritectic reaction product, that of the $\mathrm{AlMo}_{3}$ intermetallic phase. Further temperature decrease will drive the system to a second peritectic reaction to occur, that of the Mo-Ni system, forming a second zone of peritectic reaction product, that of the MoNi intermetallic phase.

It is proposed thus for the primary phase that after the initial formation of the basic $\mathrm{Cr}(\mathrm{Mo})$ core, a sequence two zones of peritectic reaction zones is following, leading to the formation of the characteristic halo configuration peripherically to the basic $\mathrm{Cr}(\mathrm{Mo})$ core.

The solidification process is concluded with the formation of the eutectic microconstituent. EDS mapping analysis (Table 1) on the eutectic region shows a significant reduction of the $\mathrm{Cr}$ content compared to that of the primary phase (from $59 \%$ to 30 at.\%). It also shows that the relative amounts of $\mathrm{Ni}, \mathrm{Al}, \mathrm{Cr}$, and Mo correspond, with good approximation, to those of the eutectic composition according to Tang et al. [15], Duprin et al. [16], Peng et al. [24], and Demirtas et al. [53]. It is, thus, proposed that the formation of the primary phase consumes significant amount of $\mathrm{Cr}$ and $\mathrm{Mo}$, leading the remaining liquid with such appropriate compositions for the formation of the final eutectic constituent. In terms of undercooling, it seems that the completion of the primary phase, raises the temperature of remaining liquid due to recalescence above T0-B2 and T0-A2, so that no decoupled growth is observed and regular eutectic structure is obtained. The development of the eutectic follows a sequence of a refined pattern at the central areas due to faster nucleation and growth kinetics and a radial development of coarser morphologies due to recalescence and heat release as the initial eutectic phases grow.

\subsubsection{Alloy C: NiAl-25Cr-15Mo}

The general view of this alloy system, as presented in Figure 1, does not seem to alter significantly from that of the previous alloy, i.e., a primary phase with the characteristic perimetric halo followed by a eutectic structure can be observed, Figure 6 . A slight difference compared to the previous alloy is the fact that the eutectic microconstituent appears to be slightly restricted. This observation is in agreement with the predictions of Peng at al. [24] where by increasing the Mo content, the system diverges from the eutectic liquid surface and the extent of the eutectic region is expected to be reduced compared to the previous alloy.

As far as the primary phase is concerned, no significant alterations of its formation sequence and mechanism can be noticed. Mo content in the primary phase core is raised (EDS analysis in Table 1) with the relative $\mathrm{Cr} / \mathrm{Mo}$ being 47/53, making Mo the dominant factor to drive the solidification events. This practically implies a sequence of further increase of the liquidus temperatures, further lowering of the necessary for nucleation undercooling, and further increase of the modified $\mathrm{T} 0-\mathrm{A} 2 \mathrm{Cr}(\mathrm{Mo})$ temperature. All these points, in conjunction with the constant low value of lattice distortion $\delta$ for the primary phase (4.87), eliminate the possibility of primary B2 phase to form and so is the case. Concerning the perimetric halo zone, as in the previous case, EDS analysis (Table 1) shows a significant increase of $\mathrm{Al}$ and $\mathrm{Ni}$ within from the core towards the perimetric zone. The relative ratio of $\mathrm{Mo} / \mathrm{Al}$ is 
$82 / 18$. This ratio, although below the $80 / 20$ ratio predicted by the Mo-Al phase diagram [52] for the peritectic reaction to occur, it is, however, very close to this limit and in conjunction with the presence of other alloying elements being present and the equilibrium conditions experienced upon manufacturing, it is possible that the peritectic reaction does occur leading, as in the case of the previous alloy, to the formation of the first zone of peritectic product ( $\mathrm{AlMo}_{3}$ intermetallic phase). Once the first peritectic zone is formed, further temperature reduction leads to the second peritectic reaction and the formation of the second peritectic zone product, that of the MoNi intermetallic.
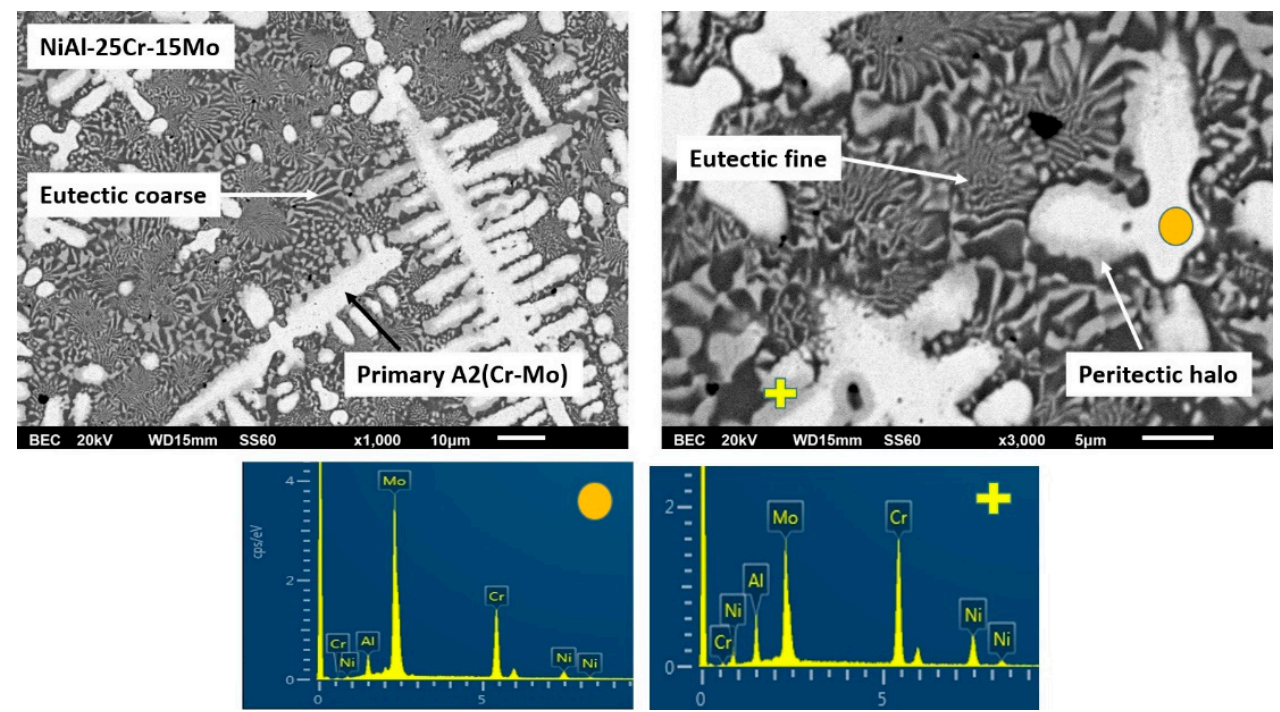

Figure 6. SEM images of higher magnification presenting the microstructural features of alloy C (NiAl-25Cr-15Mo). EDS point analysis on selective areas are also included.

Following the primary phase formation, further temperature decrease leads to the onset and development of the eutectic phases. It seems, however, that compared to the previous case, the eutectic areas are suppressed with parallel expansion of the dark phase within the lastly to solidify regions (Figure 6). This observation is a first hint that after the formation of the primary phase; the remaining liquid does not behave like a solid eutectic composition system, but rather like a hypoeutectic system. Indeed, as EDS mapping analysis within the interprimary phase regions showed that the Cr content was reduced form $\sim 31$ at.\% in the previous alloy to $\sim 21$ at.\% in the present system. Since, the interprimary area was almost entirely a eutectic phase in the previous alloy, it is logical to postulate that such dramatic $\mathrm{Cr}$ reduction shifts the compositional conditions of the remaining liquid towards hypoeutectic concentrations. As such, the solidification of the interprimary liquid follows a path of primary A2 $\mathrm{NiAl}$ and a final stage of eutectic NiAl-Cr formation.

\subsubsection{Alloy D:NiAl-20Cr-20Mo}

Further increase of Mo continues the tendency already observed for the two previous alloys, i.e., further reduction of the eutectic constituent, Figure 7. The general microstructure (Figure 1) follows the predictions of Peng et al. [24], i.e., the composition shifts further off the eutectic liquidus surface, and as such, the eutectic microconstituent should be even more reduced and so is the case.

The characteristics of the primary phase do not seem to alter significantly compared to the two previous alloys. The relative ratio of $\mathrm{Cr} / \mathrm{Mo}$ is approximately 28/72 (Table 1), which practically means that Mo more intensively controls the initiation of the solidification process. As in the previous two cases, the further increase of liquidus temperature, the subsequent undercooling decrease, and increase of T0-B2 temperature along with the persistently stable value of the lattice distortion $(\delta \sim 4.24)$ eliminate the possibility of the formation of primary $\mathrm{B} 2 \mathrm{NiAl}$ phase. As far as the peritectic halo perimetrically to the primary core, no increase of the $\mathrm{Al}$ content from the core to the periphery is observed (Table 1) and 
the relative amounts of $\mathrm{Mo} / \mathrm{Al}$ in the primary core are $89 / 11$. This ratio is significantly lower than the minimum 80/20 that could lead to the expression of the first peritectic reaction, and as such, a first zone of $\mathrm{AlMo}_{3}$ phase, as in the previous cases, is highly unlikely to have been formed. On the contrary, the second peritectic reaction proceeds regularly, and as such, the halo area consists exclusively by the MoNi intermetallic phase.
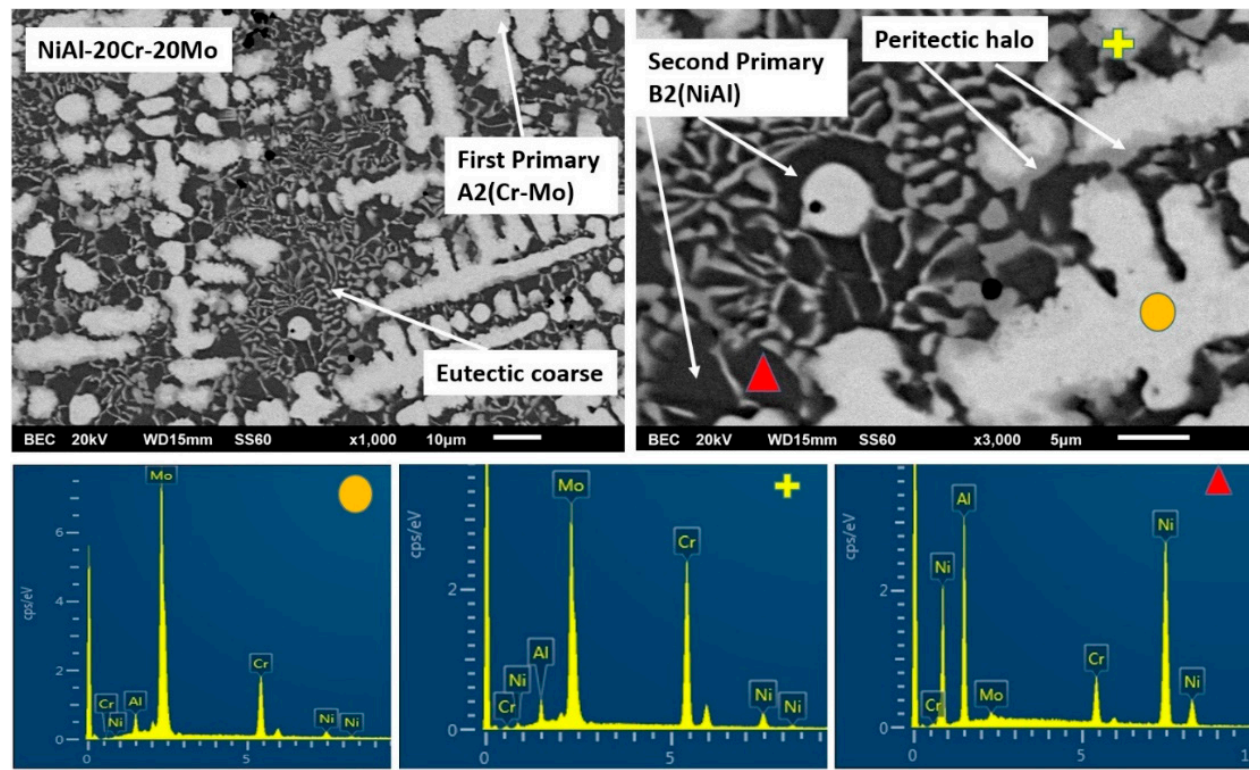

Figure 7. SEM images of higher magnification presenting the microstructural features of alloy D (NiAl-20Cr-20Mo). EDS point analysis on selective areas are also included.

What is really interesting though, about the microstructure of this alloy, is the further modification of the last to solidify liquid area. It is profound that the eutectic constituent is almost vanished. Following the approach of the previous alloys, EDS mapping in the area of the remaining liquid shows a further reduction of $\mathrm{Cr}$ to $\sim 17.5$ at.\%. This practically means that the remaining liquid composition shifts even more towards the hypoeutectic region, and as such, its solidification comprises a vast first stage of primary B2 NiAl formation, followed by a limited eutectic microconstituent. However, this $\mathrm{Cr}$ reduction is highly unlike to cause such a dramatic reduction of the eutectic phase by itself. There must be also a strong effect on the T0-B2 temperature that will affect the overall solidification procedure. The authors suspect that the presence of Mo increases both the liquidus temperatures of both sides of the Tang et al. [15] NiAl-Cr diagram. As such, the necessary for primary nucleation undercooling in the hypoeutectic area is also reduced, as in the case of the hypereutectic alloy. The T0-B2 has increased at such point that the experienced undercooling ensures the formation of primary $\mathrm{NiAl}$ phase, yet the resulting recalescence increases the remaining liquid temperature to an extent very close to the eutectic phase reaction, providing a narrow marginal temperature undercooling for the eutectic sequence. In this way, the eutectic microconstituent can be severely restricted, as observed in the present case. Alternatively or synergistically to these effects, another possible reason for this eutectic phase restriction could be the fact that because of the off-equilibrium solidification conditions, the maximum $\mathrm{Cr}$ dissolution in the NiAl-Cr phase diagram may be drifted to higher than the equilibrium values, and as such, the composition may fall within the area where no eutectic microconstituent can be developed. The authors, nevertheless, do admit that further experimentation is demanded in order to clarify this solidification behavior. 


\subsubsection{Alloy E: NiAl-15 Cr-25 Mo}

The tendency observed in the previous cases that the increase of Mo suppresses the eutectic morphology, as predicted by Peng et al. [24], it seems to be followed in the present system as well. It is profound (Figure 8) that the eutectic microconstituent is almost vanished.
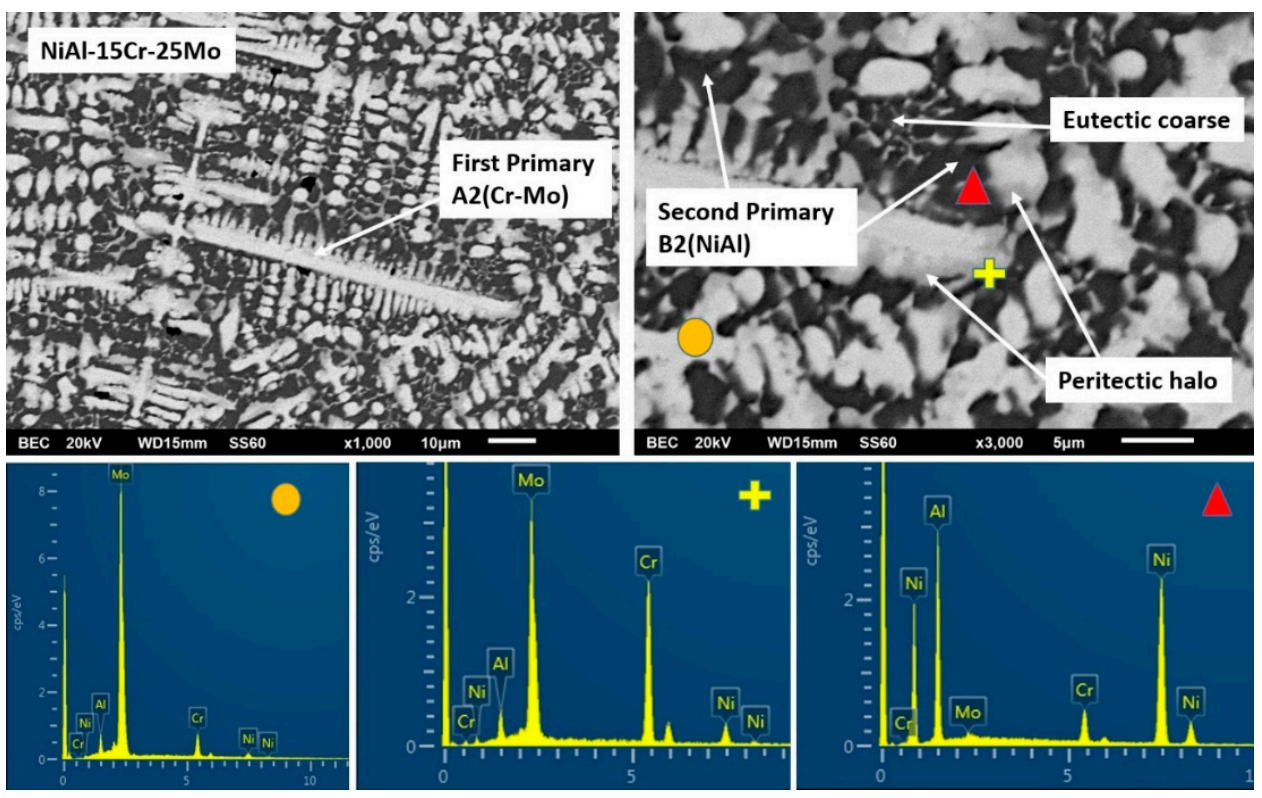

Figure 8. SEM images of higher magnification presenting the microstructural features of alloy $\mathrm{E}$ (NiAl-15Cr-25Mo). EDS point analysis on selective areas are also included.

The primary phase morphology and characteristics do not seem to differ significantly from the previous case. A relative ratio $\mathrm{Cr} / \mathrm{Mo}$ within the core of the primary phase has a value close to 24/76, and as in the previous case, Mo drives the initiation of the solidification sequence and determines the characteristics of the primary phase. Lattice distortion persists to low values ( $\sim 4.04)$ and in conjunction with the further increase of the liquids' temperature and the T0-A2 temperature, ensures the stability and the domination of the A2 phase. As far as the halo phase is concerned, the $\mathrm{Mo} / \mathrm{Al}$ ratio in the center of the core is roughly 90/10, and as such, the formation of a primary MoAl peritectic reaction product is not expected. Indeed, EDS analysis (Table 1) did not show any increase of $\mathrm{Al}$ in the halo areas, and as such, MoAl is unlikely to form. As in the previous case, a single peritectic zone of MoNi phase is established.

Questions are arisen, yet, as far as the solidification of the last liquid is concerned. EDS mapping analysis of this area revealed a further decrease of the $\mathrm{Cr}$ content close to 15 at.\%. The obtained microstructure suggests that the depletion of $\mathrm{Cr}$ by the primary phase shifts the composition of the remaining liquid even deeper to the hypoeutectic area, and following the behavior Mo may have on the liquidus and the T0-B2 temperatures, it is most likely that the experienced undercooling provided the conditions for primary B2 phase formation, yet recalescence and heat release did not provide extended undercooling conditions for eutectic constituent formation. As such, the eutectic area is further suppressed.

\subsubsection{Alloy F: NiAl-10Cr-30 Mo}

The overall microstructure is in compliance with the predictions of Peng et al. [24]. In-depth examination reveals that the morphologies do not differ significantly with the previous case; with the main conclusion being the extinguishing of the eutectic phases, as expected, for reasons described previously. 
Another important observation (Figure 9), however, that has to be mentioned is the restriction of the peritectic halo zone. A possible explanation for this phenomenon is the gradual increase of Mo from alloys (b) to (f) with a subsequent decrease of the relative Ni/Mo atomic ratio within the core of the primary phases. Indeed, based on EDS analysis (Table 1), this ratio starts with a value of Ni/Mo $\sim 22 / 78$ in the case of alloy (b) and falls down to a value of roughly 6/94 in the case of the present alloy (alloy f). According to the binary Mo-Ni phase diagram, the maximum solubility on $\mathrm{Ni}$ into Mo does not exceed a value of 2 at.\%. This practically means that even at the case of minimum $\mathrm{Ni} / \mathrm{Mo}$ ratio (6 at.\% in the present alloy), the peritectic reaction is prone to take place, yet by simple level rule considerations, the extent of the peritectic reaction product (MoNi intermetallic) is expected to be reduced, as is the actual case, observed by the microstructural features. Apart from this slight difference, no other severe microstructural modification can be distinguished.

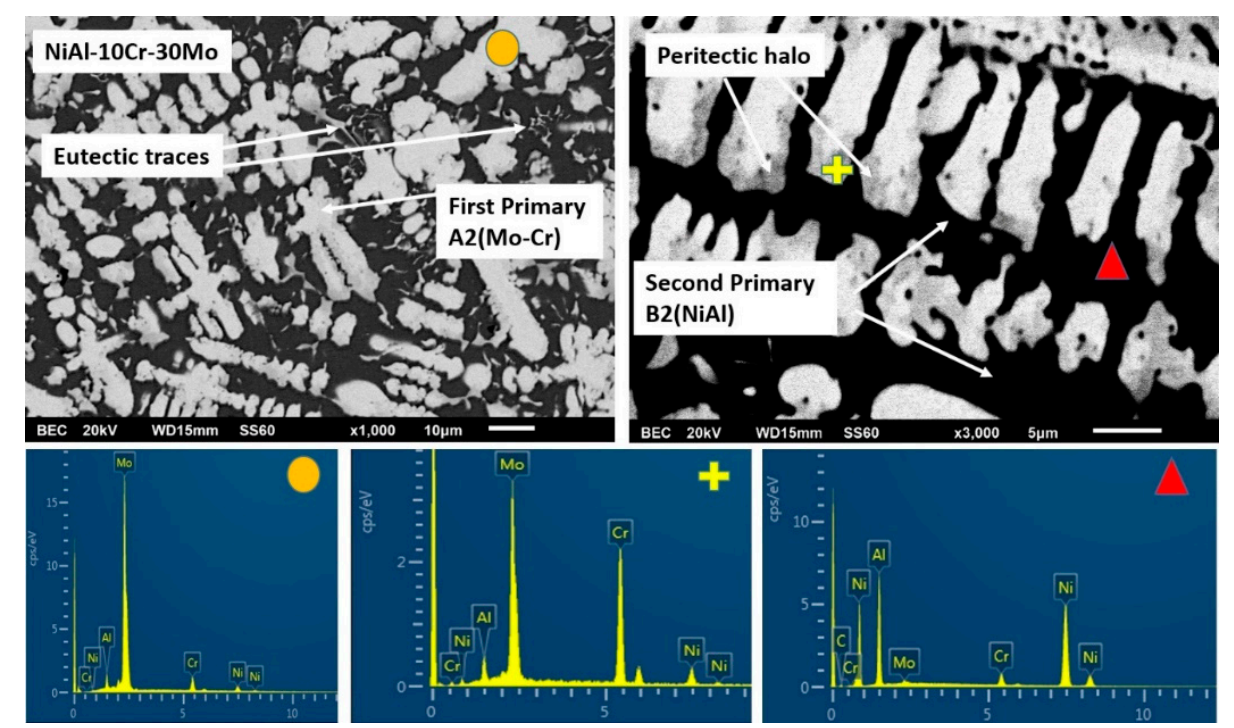

Figure 9. SEM images of higher magnification presenting the microstructural features of alloy $\mathrm{F}$ (NiAl-10Cr-30Mo). EDS point analysis on selective areas are also included.

\subsubsection{Alloy G: NiAl-40Mo}

This final alloy contains no $\mathrm{Cr}$, and as such, its microstructural features should be approached by the pseudobinary NiAl-Mo phase diagram, as proposed by Peng et al. [24]. Based on this phase diagram, there is a eutectic point of Mo composition roughly at 10 at. $\%$ and at temperature close to $1900 \mathrm{~K}$. Since the nominal composition of this alloy is 40 at.\% Mo, the system is a hypereutectic one, and as such, its microstructure should consist of primary Mo phase and a eutectic NiAl-Mo mixture. Surprisingly, as Figure 10 shows, the microstructure consists of a light primary phase, a dark phase, and a eutectic mixture. It is also interesting to notice that no halo zone peripherally to the primary light phase can be observed. EDS analysis (Table 1) shows that the light phase consists almost entirely of Mo, whereas the dark phase consists almost exclusively of $\mathrm{Ni}$ and $\mathrm{Al}$. The eutectic microconstituent is a mixture of $\mathrm{NiAl}$ and Mo. The observed microstructure strongly indicates that the pseudobinary NiAl-Mo phase diagram proposed by Peng et al. [24] is not adequate by itself to explain the solidification sequence. Based on the work of Tang et al. [15], however, it is profound that other parameters such as T0 temperatures, undercooling, and recalescence should account for the finally received microstructure. To the best of the authors knowledge, no research work is reported in the international bibliography calculating and commenting on the T0-A2 (Mo) temperature. As such, taking into consideration: a) the behavior of the NiAl-Cr system proposed of Tang et al. [15] with the described T0-B2 (NiAl) temperature, $b$ ) the fact that Peng et al. [24] proposed a similar pseudobinary $\mathrm{NiAl-Mo} \mathrm{system,} \mathrm{and} \mathrm{c)} \mathrm{the} \mathrm{perfect} \mathrm{solubility} \mathrm{between} \mathrm{Mo-Cr} \mathrm{according} \mathrm{to} \mathrm{the} \mathrm{binary} \mathrm{Mo-Cr} \mathrm{phase}$ 
diagram, the authors suspect that a correspondence T0-A2 (Mo) temperature should behave in a similar manner as that of T0-A2 (Cr) phase.
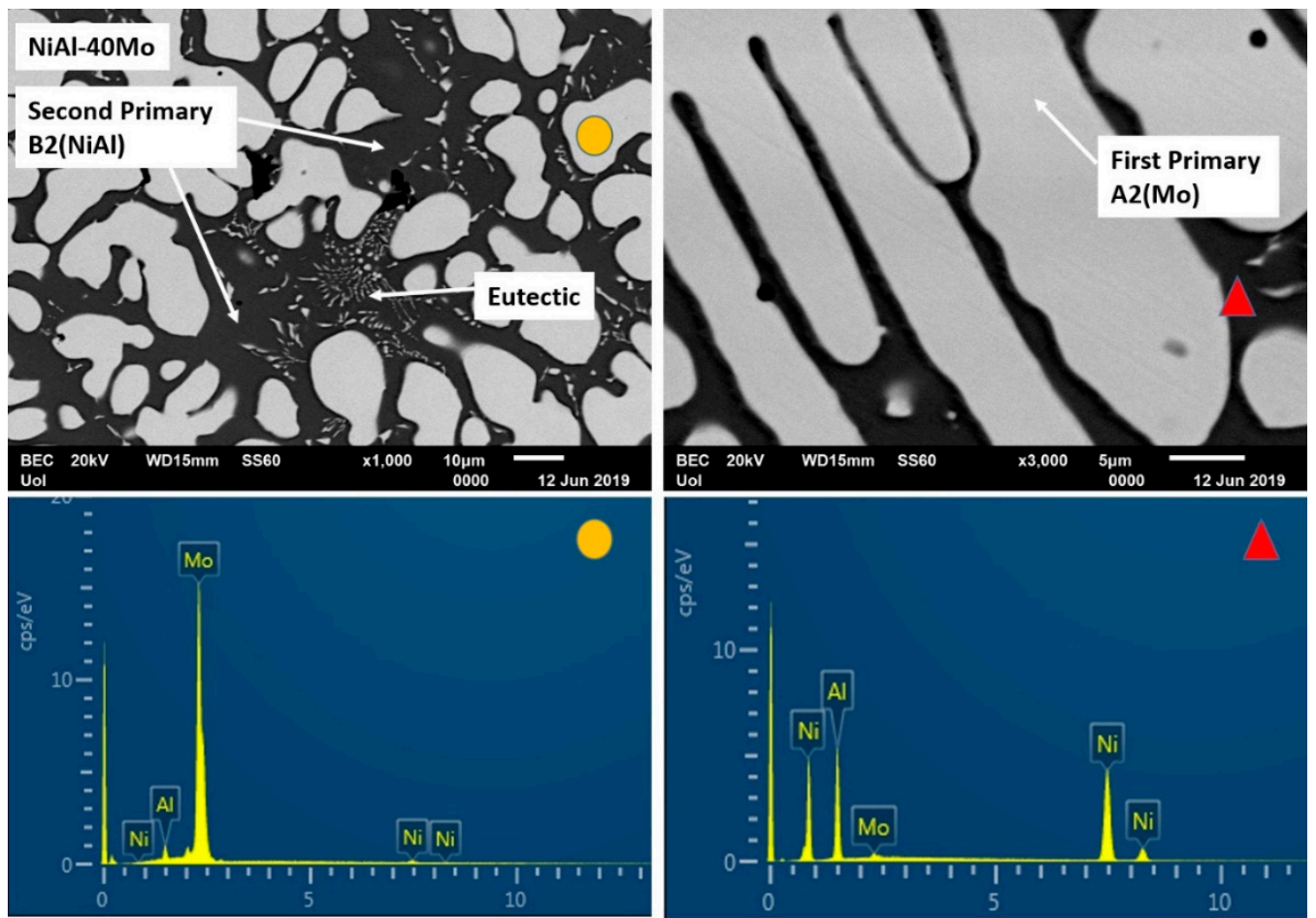

Figure 10. SEM images of higher magnification presenting the microstructural features of alloy $\mathrm{G}$ (NiAl-40Mo). EDS point analysis on selective areas are also included.

Under this phenomenologically logical assumption, the solidification sequence can be as follows:

(1) Upon solidification initiation, undercooling falls below the T0-A2 (Mo) and T0-B2 (NiAl) temperatures establishing such conditions for decoupled, partitionless growth of $\mathrm{Mo}$ and $\mathrm{NiAl}$ phases, with Mo being the first one to form due to its higher melting point.

(2) As soon as recalescence is expressed, temperature is raised so that Mo continues to grow in a partitioning to the liquid mode, whereas $\mathrm{NiAl}$ proceeds in a partitionless way.

(3) Further increase of temperature in the remaining liquid establishes conditions for partitioning growth of both $\mathrm{NiAl}$ and Mo establishing conditions for the development of the eutectic mixture growth, as the final stage of the solidification process.

Another important observation is the lack of halo zones at the periphery of the light phase, which is an indication of significant suppression of the peritectic reaction product. Indeed, as EDS analysis indicates (Table 1), the relative Ni/Mo ratio in the core of the light phase has reduced even further compared to the previous alloys, to values roughly $3 / 97$ and as such the peritectic reaction extent is further restricted to point that cannot be observed in the final microstructure.

\subsection{Microhardness and Wear Response}

Figure 11 presents the microhardness values and the wear rates of the different systems produced in the present effort. As far as the microhardness is concerned, it can be noticed that there is a gradual increase until the case of alloy $\mathrm{D}(\mathrm{NiAl}-20 \mathrm{Cr}-20 \mathrm{Mo}$ ) followed by a gradual decrease in the case of alloy $\mathrm{G}(\mathrm{NiAl}-40 \mathrm{Mo})$. This tendency is in agreement with one of the fundamental characteristics of high-entropy alloys, the so-called cocktail effect, according to which at the maximum entropic content, the systems shows exceptionally increased mechanical properties, far beyond the properties of each individual element participating in the system [54-56]. This is indeed the tendency observed in the 
present case, as alloy $\mathrm{D}$ has the maximum entropic contribution effect (Table 2), i.e., the maximum expression of the cocktail effect enhancement. This is, however, a general observation, as far as the peak microhardness of alloy $\mathrm{D}$ is concerned.

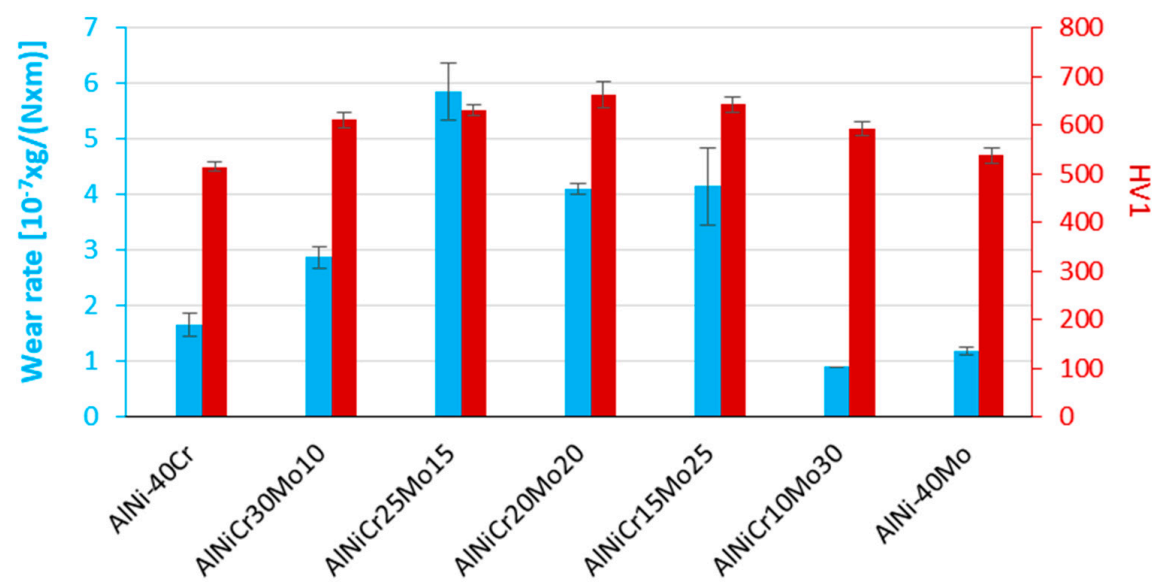

Figure 11. Microhardness values and wear rates of the different systems produced in the present effort.

Figure 12 shows the average mass loss vs. the sliding distance for each individual alloy. The first $200 \mathrm{~m}$ of the experiment were selected as a starting point for all the calculations due to the fact that, at the initial stages of the test (sliding distance between 0 and $200 \mathrm{~m}$ ), data do not follow a linear progression when listed with the following ones. Such phenomenon could be associated with the reduction of the mechanical interactions between the examined materials and the counter body ball surface as sliding evolves over longer distances. More specifically, the high pressures, which develop at each contact point, lead to the spreading or penetration of individual asperities that stimulate an irreversible change in the shape of the contacting asperities and is thus nonreproducible [57]. However, it can be easily observed when comparing data in Figure 12 with wear rate values in Figure 11 that the same trend is followed. In particular, alloys with a lower degree of mass lost during the test exhibit lower wear rates and vice versa.

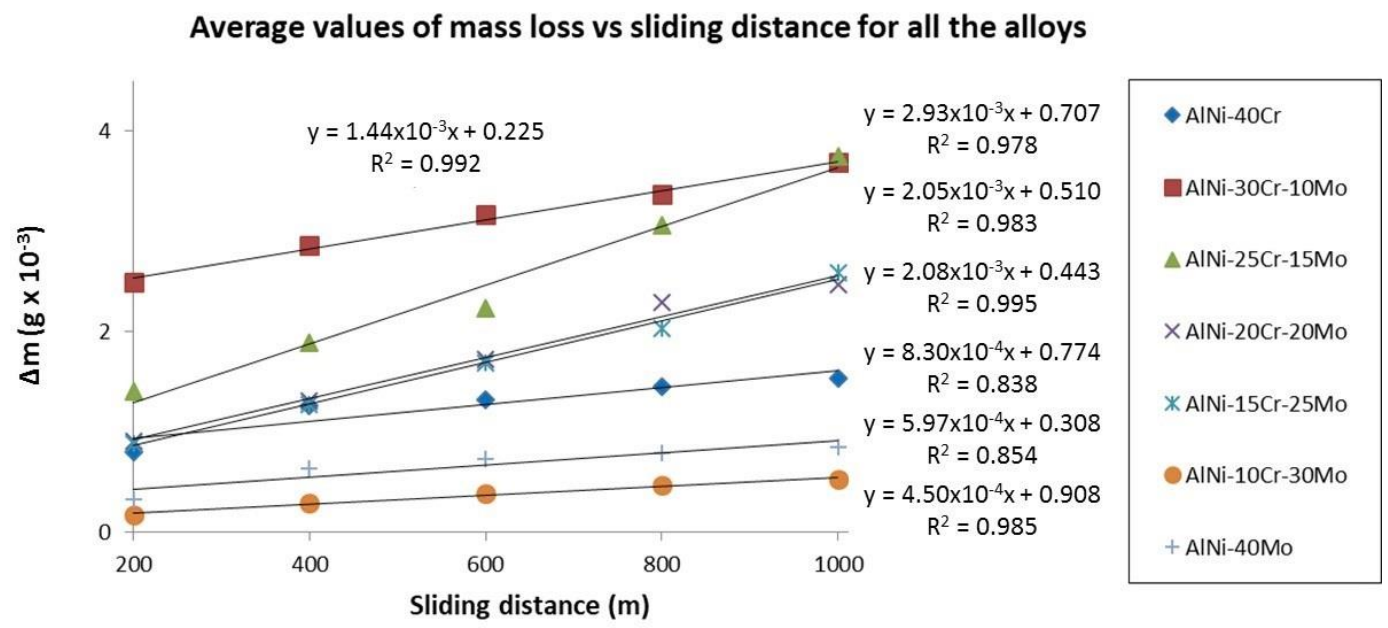

Figure 12. Average values of mass loss vs. sliding distance of the different systems produced in the present effort.

When focusing in Figure 11, an important observation is the fact that microhardness measurements and wear rates do not follow the classic trend proposed by Archard, according to which, the harder the material the lower the wear rate, i.e., the more increased its wear resistance. Due to this significant observation, the wear response of the various alloys should be approached and explained in terms of 
the microstructural and wear track morphological features. For these purposes, the authors suggest three discrete cases to explain the wear behavior:

\subsubsection{Case 1: the NiAl-Cr alloy}

Figure 13 presents various magnifications of the wear track morphology of this alloy system along with the results of EDS point analysis on selective areas. It can be observed that the material removal areas are those associated with the primary A2 and B2 phases. It seems that the interfacial area between the coarse lamellae eutectic structure and the primary A2 and B2 primary phases are regions of weakness, where upon, the sliding and shear action cannot support the primary phase grains leading an extensive material removal leading to the calculated wear rate. EDS analysis showed the presence of oxide phases, of relatively increased Fe content, within the cavities of the detached primary grains. This oxide phases are most likely debris being formed upon testing with Fe being provided by the steel ball counter body. In general, and compared with the other systems, the wear rate is relatively low. The absence of the extensive grooves along the sliding direction suggest absence of abrasive wear, with the main mechanism being the delamination-detachment mode of the primary phases, as mentioned previously.
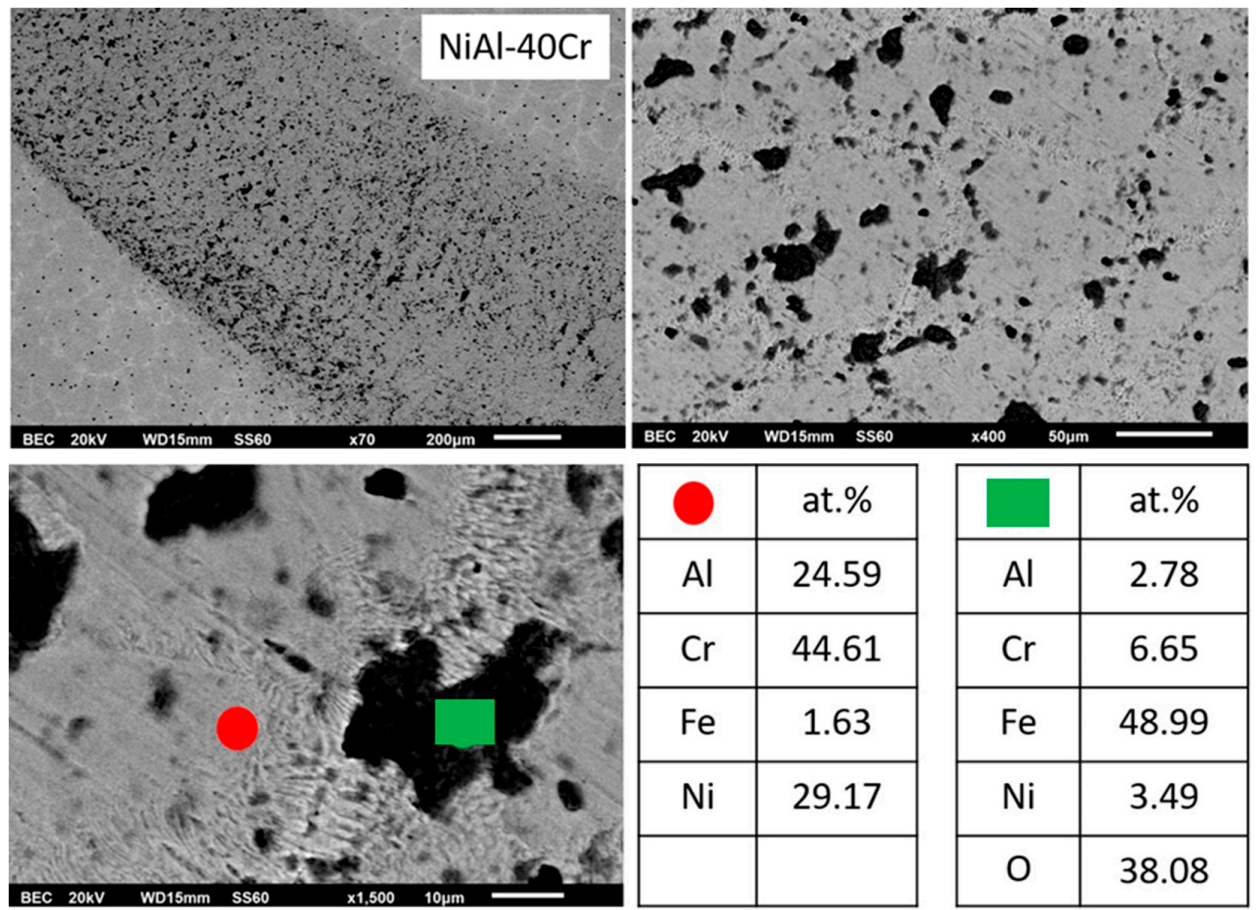

\begin{tabular}{|c|c|}
\hline $\mathrm{O}$ & at.\% \\
\hline $\mathrm{Al}$ & 24.59 \\
\hline $\mathrm{Cr}$ & 44.61 \\
\hline $\mathrm{Fe}$ & 1.63 \\
\hline $\mathrm{Ni}$ & 29.17 \\
\hline & \\
\hline
\end{tabular}

\begin{tabular}{|c|c|}
\hline & at.\% \\
\hline $\mathrm{Al}$ & 2.78 \\
\hline $\mathrm{Cr}$ & 6.65 \\
\hline $\mathrm{Fe}$ & 48.99 \\
\hline $\mathrm{Ni}$ & 3.49 \\
\hline $\mathrm{O}$ & 38.08 \\
\hline
\end{tabular}

Figure 13. SEM images of different magnifications showing the characteristic features of the wear track morphology of alloy A (NiAl-40Cr). Tables of EDS point analysis measurements in selective areas are also included.

\subsubsection{Case 2: alloys with progressively increasing Mo content with $\mathrm{Cr}$ being present (alloys B to $\mathrm{F}$ )}

The introduction of Mo, resulted in the expression of an obscure situation: despite the fact that the presence of Mo leads to an increase of microhardness, the wear resistance does not seem to follow the same trend. A close examination of the wear track morphologies of these systems (Figures 14-18) reveals a series of interesting points, as follows:

(1) A peak value of the wear rate is observed for alloy B, which is gradually reduced until the case of alloy F. This practically means that the introduction of small amount of Mo bursts the wear rate at very high values, yet the progressive increase of the Mo content leads to a gradual reduction of the wear rates. 
(2) All wear tracks (Figures 14-18) show an extensive material loss at the areas of the lastly solidified liquid, irrespectively of this area's morphological feature (being a eutectic microconstituent or not). This observation is very crucial as it suggests that the interfacial areas between the lastly to solidify liquid and the primary phases are weak and their rigidity is highly questionable.

(3) The oxide phases being present within the cavities of the removed materials are also of great importance. EDS analysis (Figures 14-18) on these selective areas shows that in the case of alloy $\mathrm{B}$, the oxides phases (debris formed upon testing) are a mixture of Fe and Cr oxides. As the Mo content increases, the composition of these oxides is altered. In alloy $\mathrm{C}$, the oxide phases are rich in Fe rather in $\mathrm{Cr}$, and in the case of alloy $\mathrm{D}$, the Mo content of the oxide phases is taking the lead. Further increase of Mo, alloy E, shows that the Ni is the dominant element followed by Fe. The Cr content is significantly reduced. Finally, in the case of alloy F, the Ni content is further increased and the $\mathrm{Cr}$ content is further reduced. As it will be discussed in a following paragraph, these elemental variations play a vital role on the lubricating action of the oxide phases being formed.

(4) Even among these alloys, a classification of their wear rates can be conducted: alloys B and C forming the first group of high wear rates, alloys D and E forming a second group with reduced wear rates, and finally alloy $\mathrm{F}$ with considerably reduced wear rate. There must be a reason for this kind of transition which will be addressed later.

(5) Another observation that will help in the explanation of the wear behavior of the different systems is the morphology of the primary phases and, especially, the morphology of the contour of the primary phases. By recalling the involved microstructures (Figures 5-9), it can be observed that the periphery of the primary phases in the cases of alloys B to E is characterized by an intensive jigsaw like morphology with acicular protrusions towards the lastly to solidify liquid. Alloy G shows a more planar, yet smoother perimetric contour of the primary phase.
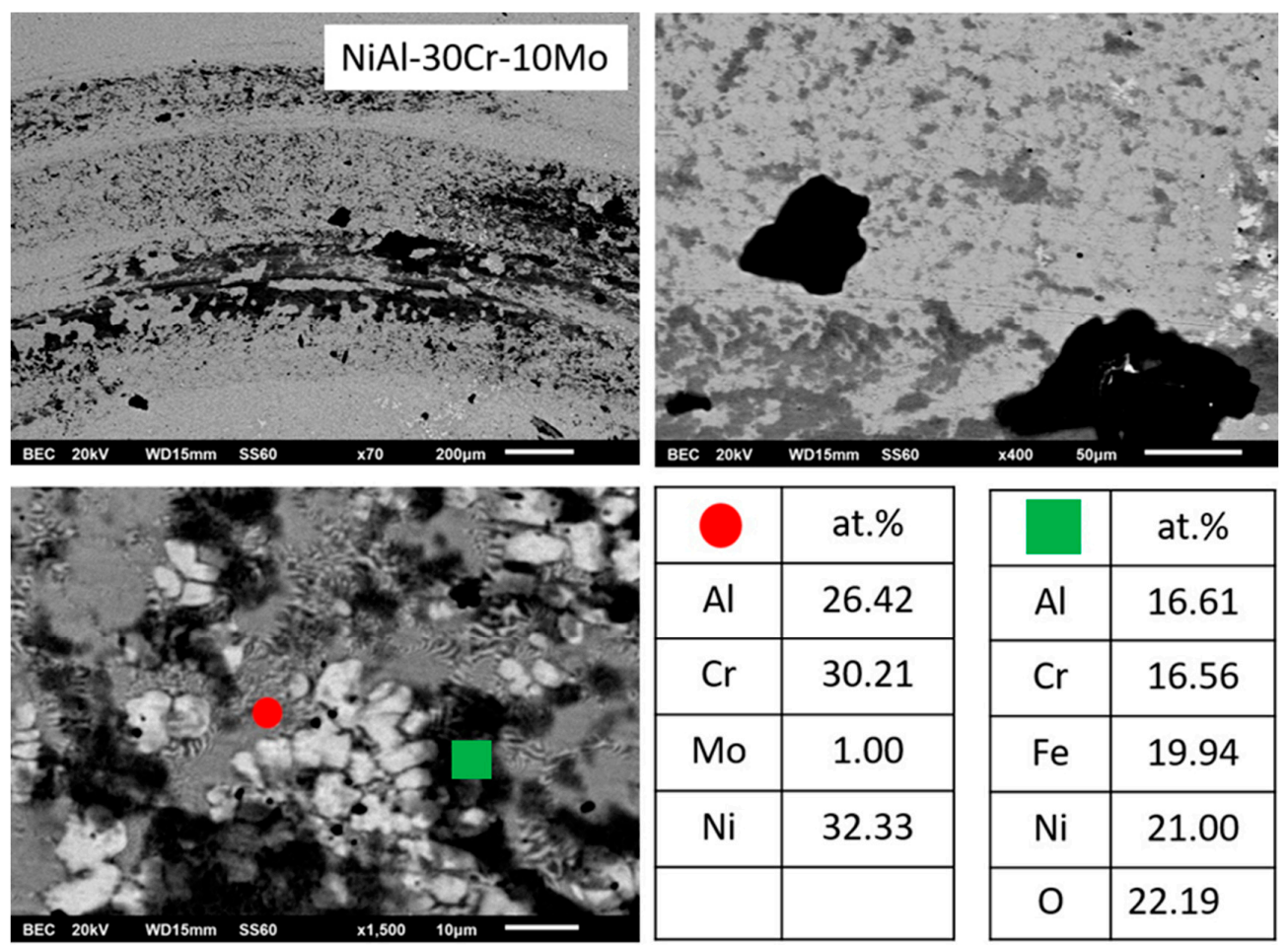

\begin{tabular}{|c|c|}
\hline $\mathrm{O}$ & at.\% \\
\hline $\mathrm{Al}$ & 26.42 \\
\hline $\mathrm{Cr}$ & 30.21 \\
\hline $\mathrm{Mo}$ & 1.00 \\
\hline $\mathrm{Ni}$ & 32.33 \\
\hline & \\
\hline
\end{tabular}

\begin{tabular}{|c|c|}
\hline & at.\% \\
\hline $\mathrm{Al}$ & 16.61 \\
\hline $\mathrm{Cr}$ & 16.56 \\
\hline $\mathrm{Fe}$ & 19.94 \\
\hline $\mathrm{Ni}$ & 21.00 \\
\hline $\mathrm{O}$ & 22.19 \\
\hline
\end{tabular}

Figure 14. SEM images of different magnifications showing the characteristic features of the wear track morphology of alloy B (NiAl-30Cr-10Mo). Tables of EDS point analysis measurements in selective areas are also included. 

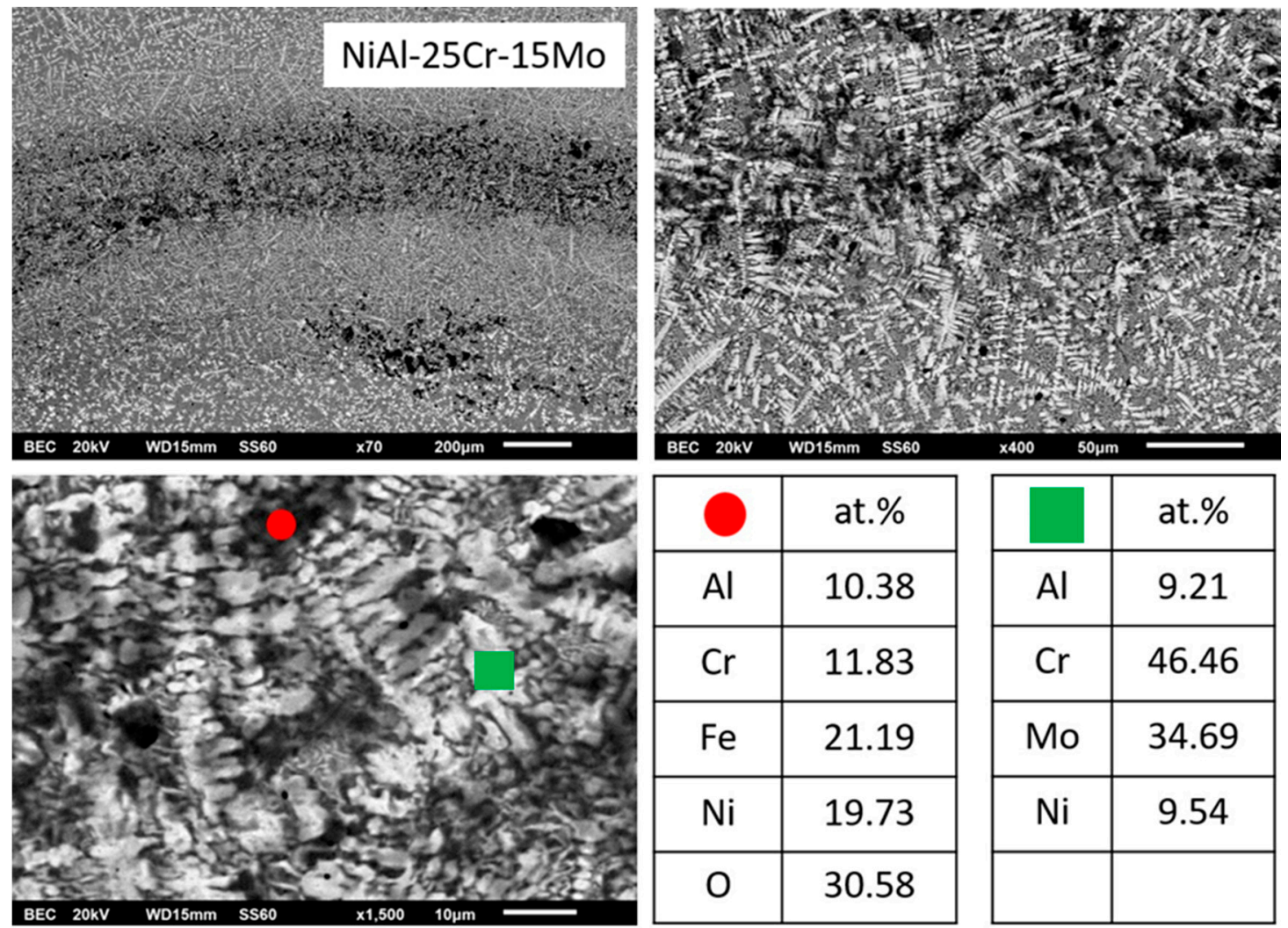

\begin{tabular}{|c|c|}
\hline $\mathrm{O}$ & at.\% \\
\hline $\mathrm{Al}$ & 10.38 \\
\hline $\mathrm{Cr}$ & 11.83 \\
\hline $\mathrm{Fe}$ & 21.19 \\
\hline $\mathrm{Ni}$ & 19.73 \\
\hline $\mathrm{O}$ & 30.58 \\
\hline
\end{tabular}

\begin{tabular}{|c|c|}
\hline & at.\% \\
\hline $\mathrm{Al}$ & 9.21 \\
\hline $\mathrm{Cr}$ & 46.46 \\
\hline $\mathrm{Mo}$ & 34.69 \\
\hline $\mathrm{Ni}$ & 9.54 \\
\hline & \\
\hline
\end{tabular}

Figure 15. SEM images of different magnifications showing the characteristic features of the wear track morphology of alloy C (NiAl-25Cr-15Mo). Tables of EDS point analysis measurements in selective areas are also included.
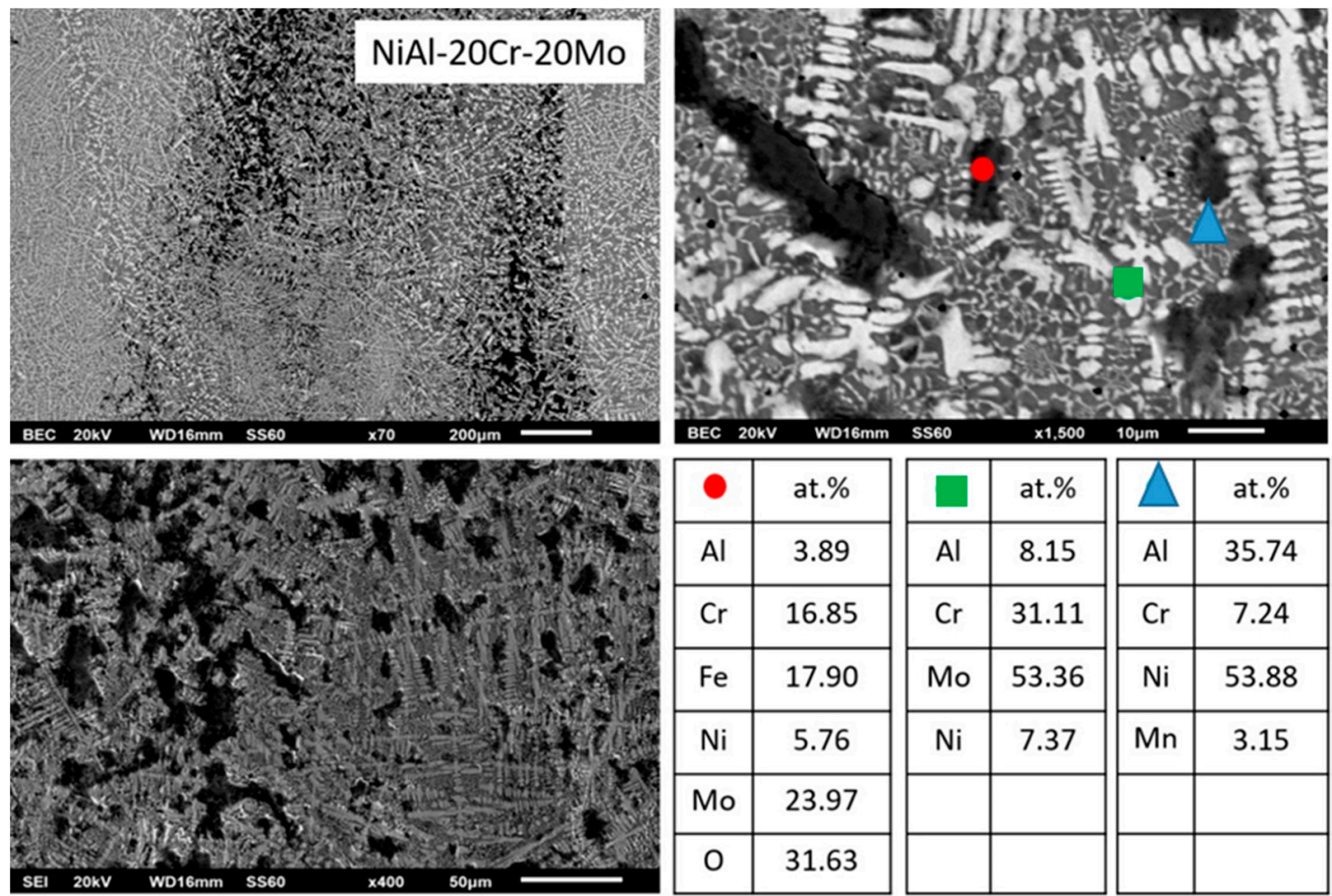

\begin{tabular}{|c|c|c|c|c|c|}
\hline$\bullet$ & at.\% & & at.\% & $\triangle$ & at.\% \\
\hline $\mathrm{Al}$ & 3.89 & $\mathrm{Al}$ & 8.15 & $\mathrm{Al}$ & 35.74 \\
\hline $\mathrm{Cr}$ & 16.85 & $\mathrm{Cr}$ & 31.11 & $\mathrm{Cr}$ & 7.24 \\
\hline $\mathrm{Fe}$ & 17.90 & $\mathrm{Mo}$ & 53.36 & $\mathrm{Ni}$ & 53.88 \\
\hline $\mathrm{Ni}$ & 5.76 & $\mathrm{Ni}$ & 7.37 & $\mathrm{Mn}$ & 3.15 \\
\hline $\mathrm{Mo}$ & 23.97 \\
\hline $\mathrm{O}$ & 31.63 \\
\hline & & & & \\
\hline & & & \\
\hline
\end{tabular}

Figure 16. SEM images of different magnifications showing the characteristic features of the wear track morphology of alloy D (NiAl-20Cr-20Mo). Tables of EDS point analysis measurements in selective areas are also included. 

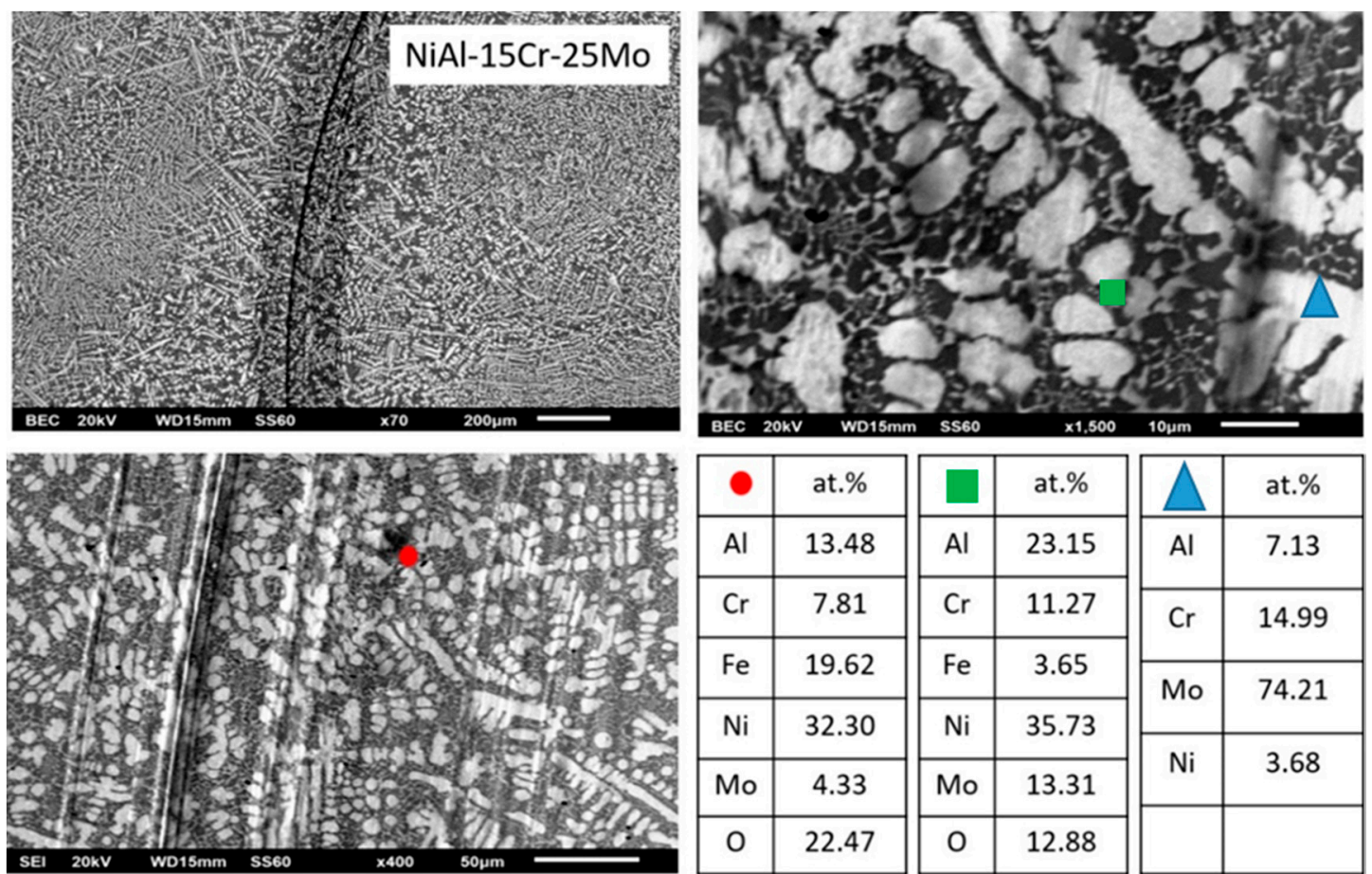

\begin{tabular}{|c|c|c|c|c|c|}
\hline O & at.\% & & at.\% & $\Lambda$ & at.\% \\
\hline Al & 13.48 & Al & 23.15 & $\mathrm{Al}$ & 7.13 \\
\hline $\mathrm{Cr}$ & 7.81 & $\mathrm{Cr}$ & 11.27 & $\mathrm{Cr}$ & 14.99 \\
\hline $\mathrm{Fe}$ & 19.62 & $\mathrm{Fe}$ & 3.65 & \multirow{2}{*}{ Mo } & \multirow{2}{*}{74.21} \\
\hline $\mathrm{Ni}$ & 32.30 & $\mathrm{Ni}$ & 35.73 & & \\
\hline Mo & 4.33 & Mo & 13.31 & $\mathrm{Ni}$ & 3.68 \\
\hline 0 & 22.47 & 0 & 12.88 & & \\
\hline
\end{tabular}

Figure 17. SEM images of different magnifications showing the characteristic features of the wear track morphology of alloy E (NiAl-15Cr-25Mo). Tables of EDS point analysis measurements in selective areas are also included.
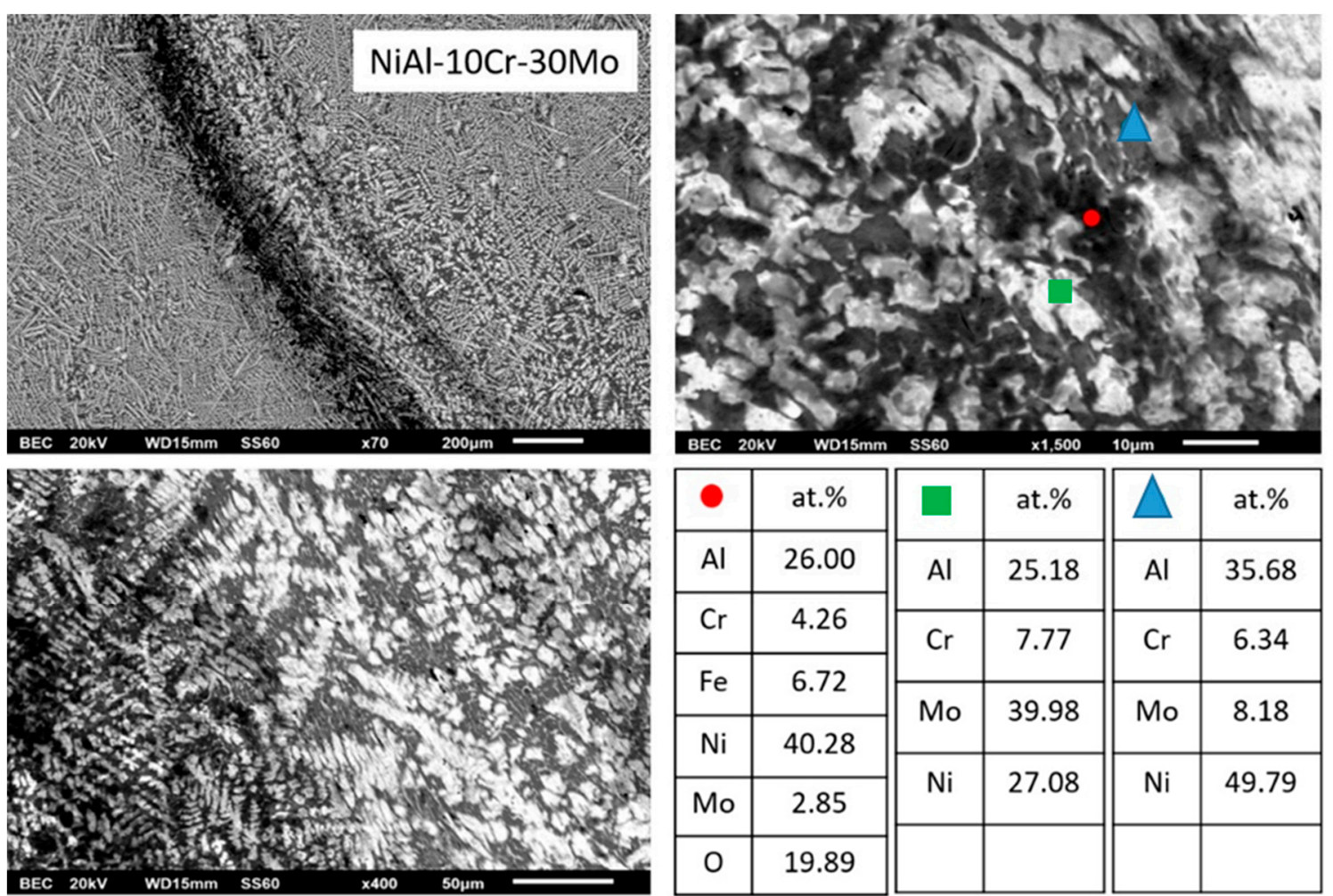

\begin{tabular}{|c|c|c|c|c|c|}
\hline - & at.\% & 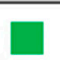 & at.\% & $A$ & at.\% \\
\hline $\mathrm{Al}$ & 26.00 & $\mathrm{Al}$ & 25.18 & Al & 35.68 \\
\hline $\mathrm{Cr}$ & 4.26 & \multirow{2}{*}{$\mathrm{Cr}$} & \multirow{2}{*}{7.77} & \multirow{2}{*}{$\mathrm{Cr}$} & \multirow{2}{*}{6.34} \\
\hline \multirow{2}{*}{$\mathrm{Fe}$} & \multirow{2}{*}{6.72} & & & & \\
\hline & & \multirow[t]{2}{*}{ Mo } & \multirow{2}{*}{39.98} & \multirow[t]{2}{*}{ Mo } & \multirow[t]{2}{*}{8.18} \\
\hline $\mathrm{Ni}$ & 40.28 & & & & \\
\hline Mo & 2.85 & $\mathrm{Ni}$ & 27.08 & $\mathrm{Ni}$ & 49.79 \\
\hline 0 & 19.89 & & & & \\
\hline
\end{tabular}

Figure 18. SEM images of different magnifications showing the characteristic features of the wear track morphology of alloy $\mathrm{F}$ (NiAl-10Cr-30Mo). Tables of EDS point analysis measurements in selective areas are also included. 
Based on these important observations, a possible explanation of this category of system wear response could be as follows:

(1) The first crucial factor, as already mentioned, is the nature of the oxides formed. The observed oxides in these systems are Fe-based, Ni-based, Mo-based, and Cr-based oxides. According to the extensive reviews of Glascott et al. [58] and Stott and Wood [59], among these oxides, the most effective in performing lubricating action are the $\mathrm{Fe}-, \mathrm{Ni}-$, and $\mathrm{Mo}-$ based oxides which belong to the category of the so-called ductile oxides. Glascott et al. [58] postulates that these oxides under conditions of hydrostatic pressure show significant ductile behavior and can deform plastically. Glascott et al. [58] also mention that under sliding wear conditions, a high portion of hydrostatic pressure field (even as high as $60 \%$ of the overall stress field) especially at the areas of oxide asperity junctions, exists. Under this frame, the ductile oxides deform plastically and absorb a great amount of the shear stresses involved energy and provide to the system an effective lubrication action. Cr-based oxides on the other hand, despite the fact that they are harder, they are also very brittle and do not deform plastically as the other oxides, and as such, their lubrication action is limited. Stott et al. [59] also mentioned that another problem with the Cr-based oxides is their poor adhesion with the substrate especially in the case of $\mathrm{Ni}-\mathrm{Cr}$ containing alloys. If we recall not the present experimental findings, it can be seen, in reverse order, in the alloys of high Mo content (alloys G, E, and D) that the oxides being formed are mainly Mo, Ni, and Fe-based, whereas the presence of Cr-based is very restricted. It is expected, thus, that in these systems, the oxides been present will perform a strong lubrication action. In the case of alloys $\mathrm{C}$ and $\mathrm{B}$, it can be observed that the relative amounts of $\mathrm{Cr}$ are increased and as such, the lubricating action is reduced.

(2) The severe mass loss, as already mentioned, is related to the extensive detachment of the last to solidify liquid areas. It should, hence, be a gradual weakening of the interfacial area between the primary phases and these lastly solidified regions. The difference between alloy A and alloys B to F, concerning these interfacial areas, is the presence of peritectic halos around the primary phases. As mentioned previously, the result of these peritectic reactions is the formation of strong and brittle intermetallic phases. Taking into consideration that as the Mo content increases from alloys $\mathrm{B}$ to $\mathrm{C}$, the second primary phase to be formed is the $\mathrm{NiAl}$ intermetallic phase; Figure 19 shows a graphical representation of the possible epitaxial mismatches between the phases gradually formed from the core of the primary phases, through the formation of the peritectic halo intermetallics, to the last formation of the secondary primary NiAl. Alloys B and C belong to the first category of phase formation (Figure 19a) where both the peritectic intermetallics are present and the epitaxial mismatch starts from $\sim 10 \%$, reduced to $\sim 8 \%$, and finally, to $\sim 2 \%$ at the outer layers. On the contrary, alloys $\mathrm{D}$ and $\mathrm{E}$ did not show the formation of the first peritectic halo reaction zone, and as such, the epitaxial mismatch (Figure 19b) starts with values as low as $\sim 1 \%$ moving to $\sim 2 \%$ at the outer layer. Intensive epitaxial mismatch can be a reason for intensive residual stresses being developed, and as such, the integrity and the stability of the interfacial areas are strongly and negatively affected [60]. This postulate is in agreement with the experimental findings of this effort. The interfacial rigidity in the case of alloys $B$ and $C$ is more affected due to the higher values of epitaxial mismatches, and as such, the danger of a detachment event is highly increased. On the contrary, the progression from the primary phase to the last solidified areas is smother in the case of alloys D and E, in terms of interfacial stability, and as such, the possibility of a forthcoming detachment event is reduced. Indeed, this is what is actually observed in the present case where alloys $B$ and $C$ showed significant material loss events in the last solidified regions compared to the same phenomenon in the case of alloys D and E. Furthermore, in the case of alloy F where the formation of peritectic halo is limited, the wear rate is further decreased. 


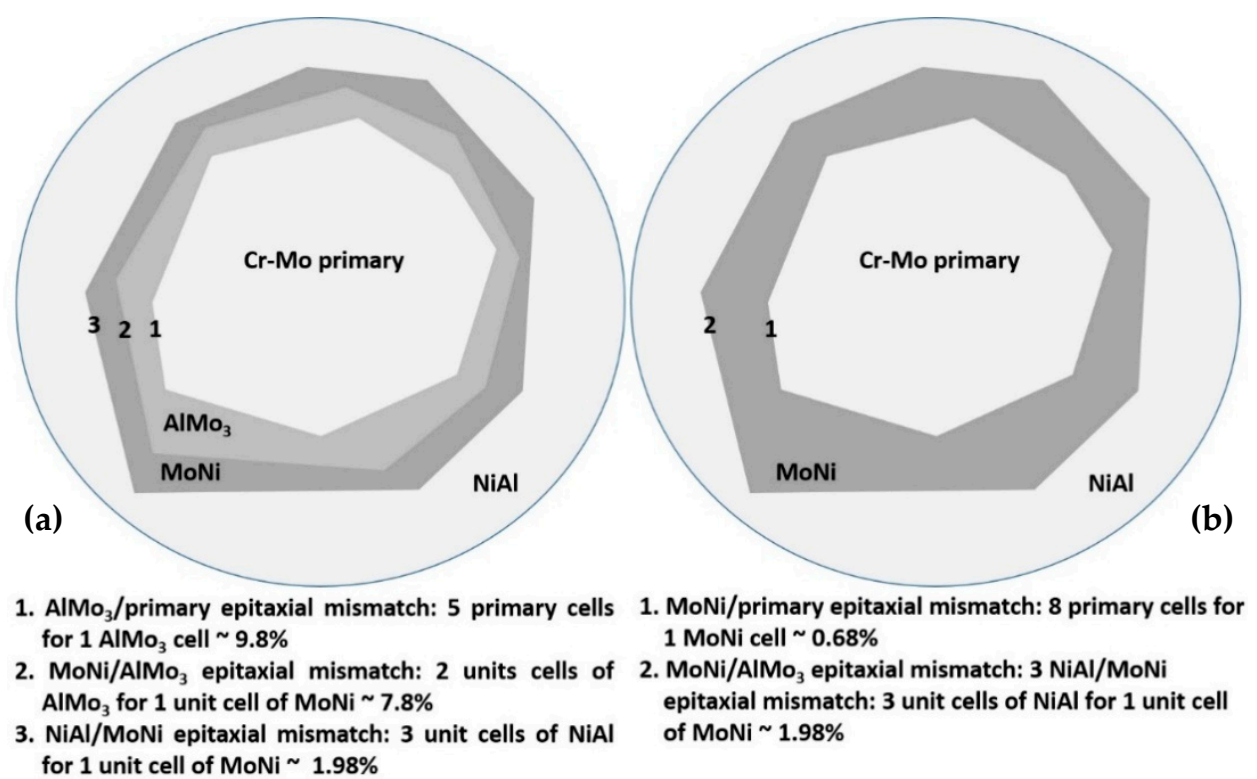

Figure 19. A schematic representation of the epitaxial mismatch evolution due to the presence of intermetallic phases. (a) sketch is related to the presence of both the peritectic intermetallic phases $\left(\mathrm{AlMo}_{3}\right.$ and $\mathrm{MoNi}$ ) and refers to alloys $\mathrm{B}, \mathrm{C}$, and $\mathrm{D}$. (b) sketch is related to the presence of single peritectic intermetallic phase $(\mathrm{MoNi})$ and refers to alloys $\mathrm{E}$ and F. Notice that the calculated values are the minimum ones, in both cases. Calculations were based on crystal lattice data provided by the PDF phase cards during the XRD analysis.

The presence of intermetallic phases perimetrically to the primary grains, can also affect the integrity of the interfacial areas in other terms. As mentioned previously, the contour of the primary phases in alloys B to $\mathrm{F}$ has a strong acicular jigsaw morphology. This aggressive landscape can also establish a field of high residual stresses that may lead to a premature collapsing of the interfacial area. The acicular morphologies are also the result of the formation of intermetallic phases, which according to the classic nucleation theory shows increased values of the so-called Jackson factor (over the value of 2), which is an indication of a faceted growth of mode that, in turn, leads to the formation of such kind of acicular morphologies [61].

\subsubsection{Case 3: the NiAl-40Mo Alloy}

Based on the remarks mentioned for the alloys in the previous case, in this alloy, the dominant oxides are $\mathrm{Ni}, \mathrm{Fe}$, and $\mathrm{Mo}$ (Figure 20), i.e., oxides of high lubricating action. Additionally, no significant evidence for the formation of intermetallic peritectic halos can be distinguished, which means that no epitaxial mismatch residual stress field is established that can weaken the interfacial area between the primary phases and the last to solidify liquid. Furthermore, the contour of the primary phases, exactly due to the absence of intermetallic phases, is smooth and rounded and as such no further negative effect on residual stress field building up by acicular morphologies takes place.

In summary, the wear response of the alloys produced on the present effort is a combination of the factors reported previously, i.e., the nature and chemistry of the surface oxides and the presence, the nature, and the morphological features of intermetallic phases. It has to mentioned, nevertheless, that examination of cross section areas related to the wear tracks, as adopted in other experimental efforts [62,63], would provide a further insight on the wear phenomena and such an assessment is currently being undertaken. 

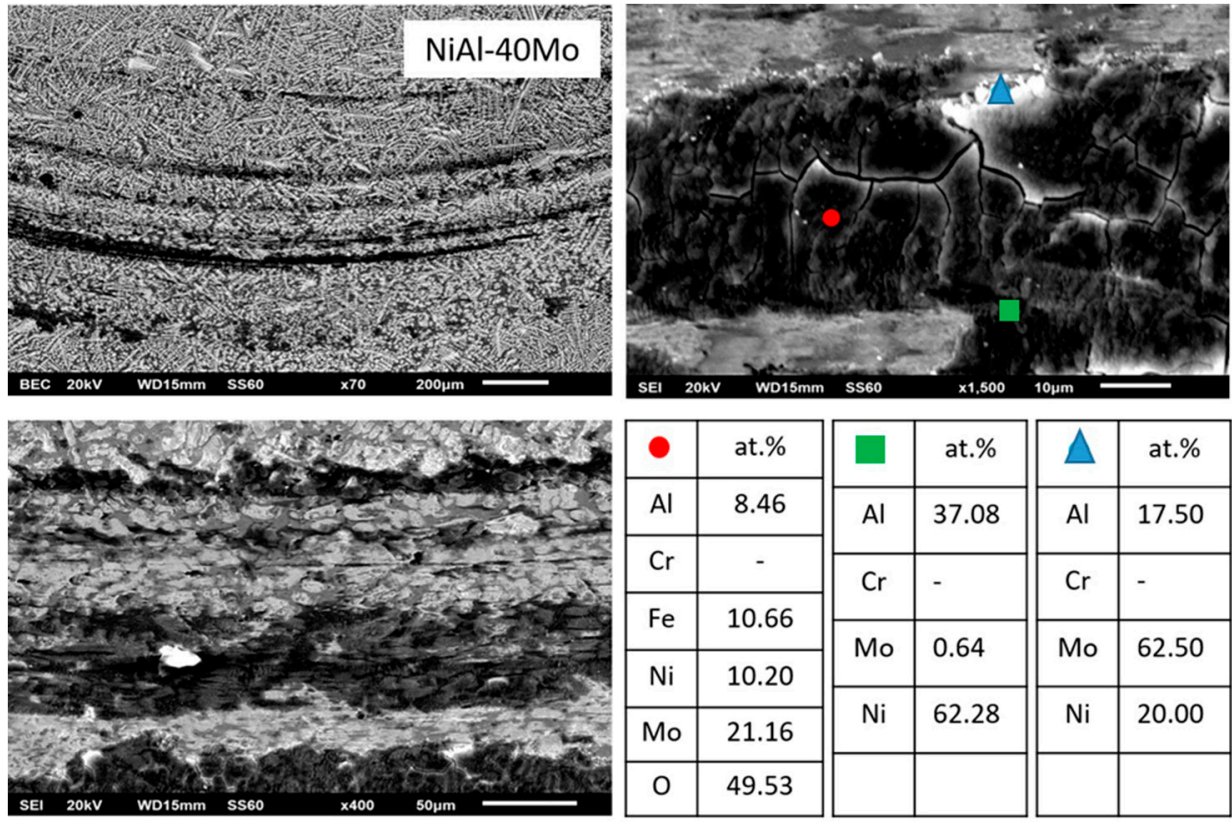

\begin{tabular}{|c|c|c|c||c|c|}
\hline$\bullet$ & at.\% & & at.\% & $\Delta$ & at.\% \\
\hline Al & 8.46 & $\mathrm{Al}$ & 37.08 & $\mathrm{Al}$ & 17.50 \\
\hline $\mathrm{Cr}$ & - & $\mathrm{Cr}$ & - & $\mathrm{Cr}$ & - \\
\hline $\mathrm{Fe}$ & 10.66 & $\mathrm{Mo}$ & 0.64 & $\mathrm{Mo}$ & 62.50 \\
\hline $\mathrm{Ni}$ & 10.20 & $\mathrm{No}$ & & \\
\hline $\mathrm{Mo}$ & 21.16 & $\mathrm{Ni}$ & 62.28 & $\mathrm{Ni}$ & 20.00 \\
\hline $\mathrm{O}$ & 49.53 & & & & \\
\hline
\end{tabular}

Figure 20. SEM images of different magnifications showing the characteristic features of the wear track morphology of alloy A (NiAl-40Mo). Tables of EDS point analysis measurements in selective areas are also included.

\section{Concluding Remarks}

\subsection{Microstructural Features}

(1) The microstructure of the NiAl-40Cr alloy is a result of solidification sequence according to which primary $\mathrm{A} 2(\mathrm{Cr})$ and $\mathrm{B} 2(\mathrm{NiAl})$ phases are developed partitionless due to undercooling phenomenon. Recalescence and its involved heat release lead to the development of a final eutectic structure.

(2) The substitution of $\mathrm{Cr}$ by $10 \% \mathrm{Mo}$, in the case of alloy B, stabilizes the A2 phase as a primary phase as both Mo and undercooling do not favor a parallel B2 growth in a partitionless way. Phase diagram predictions verified in practice and multiple $\mathrm{AlMo}_{3}$ and $\mathrm{MoNi}$ intermetallic phases are developed at the periphery of the primary grains due to peritectic reactions. Recalescence leads to the final stage of eutectic phase formation.

(3) By increasing the Mo content in all the preceding alloys, the A2 phase is further established as the primary phase, $\mathrm{AlMo}_{3}$ is eventually vanished, and the eutectic phase is continuously restricted. B2 (NiAl) is gradually increased as a secondary (following A2) "primary" phase. All these microstructural sequences are related to partitioning/partitionless growth, recalescence, and undercooling phenomenon.

(4) The NiAl-40Mo alloy consists of primary Mo, NiAl, and NiAl-Mo eutectic constituents. The same phenomena, as in the previous cases, are responsible for this solidification sequence.

(5) The increase of the Mo content leads to progressive elimination of the eutectic microconstituent and establishes significantly simpler microstructures of greater controlling potential.

\subsection{Sliding Wear Response}

(1) The sliding wear behavior of alloy NiAl-40Cr showed extensive material loss due to localized delamination of the eutectic areas. Oxides of $\mathrm{Fe}$ and $\mathrm{Cr}$ are the main oxides being present.

(2) An increased wear rate was observed in the case of alloy B (NiAl-30Cr-10Mo) by extensive material loss at the eutectic areas, due to the presence of intermetallic peritectic halos and the nonlubricating action of the formed oxides. The increase of the Mo content leads to the reduction 
of the wear rate (from alloy B to alloy F), due to the gradual restriction of the intermetallic phases and the gradual formation of oxides phases with intensive lubrication action.

(3) The NiAl-40Mo is characterized by a relatively low wear rate due to the absence of intermetallic phases and the presence of lubricating oxides.

Author Contributions: Conceptualization, A.E.K. and E.G.; methodology, A.E.K., E.G., C.M.; validation, A.E.K., E.G. and C.M.; investigation, C.M., K.G. and A.P.; data curation, C.M., K.G. and A.P.; writing of the original draft preparation, C.M. and A.E.K.; writing of review and editing, C.M. and A.E.K.; visualization, A.P.; supervision, A.E.K.; project administration, A.E.K. and E.G.; funding acquisition, C.M. All authors have read and agreed to the published version of the manuscript.

Funding: This research is cofinanced by Greece and the European Union (European Social Fund-ESF) through the Operational Programme (Human Resources Development, Education and Lifelong Learning) in the context of the project "Strengthening Human Resources Research Potential via Doctorate Research" (MIS-5000432), implemented by the State Scholarships Foundation (IK $\Upsilon$ ).

Conflicts of Interest: The authors would like to declare no conflict of interest.

\section{Appendix A. Parametric Models}

Three critical values have been initially proposed to govern the formation of disordered solid solutions in HEAs [29]: atomic size difference ( $\delta)$, enthalpy of mixing $\left(\Delta \mathrm{H}_{\mathrm{mix}}\right)$, and entropy of mixing $\left(\Delta \mathrm{S}_{\text {mix }}\right)$ between the alloying elements of the derived phases.

These three parameters were defined by Equations (A1)-(A3), respectively:

$$
\delta=100 \sqrt{\sum_{\mathrm{i}=1}^{\mathrm{n}} \mathrm{c}_{\mathrm{i}}\left(1-\frac{\mathrm{r}_{\mathrm{i}}}{\overline{\mathrm{r}}}\right)^{2}}
$$

where, $\overline{\mathrm{r}}=\sum_{i=1}^{\mathrm{n}} \mathrm{c}_{\mathrm{i}} \mathrm{r}_{\mathrm{i}}$ and $\mathrm{c}_{\mathrm{i}}$ and $\mathrm{r}_{\mathrm{i}}$ are the atomic percentage and atomic radius of the $\mathrm{i}^{\text {th }}$ element, respectively. The numerical factor 100 is used to amplify the data for clarity;

$$
\Delta \mathrm{H}_{\text {mix }}=\sum_{\mathrm{i}=1, \mathrm{i} \neq \mathrm{j}}^{\mathrm{n}} \Omega_{\mathrm{ij}} \mathrm{c}_{\mathrm{i}} \mathrm{c}_{\mathrm{j}}
$$

where $\Omega_{\mathrm{ij}}=4 \Delta \mathrm{H}_{\text {mix }}{ }^{\mathrm{AB}}$ and $\Delta \mathrm{H}_{\text {mix }}{ }^{\mathrm{AB}}$ is the mixing enthalpy of binary liquid $\mathrm{AB}$ alloys; and

$$
\Delta \mathrm{S}_{\text {mix }}=-\mathrm{R} \sum_{\mathrm{i}=1}^{\mathrm{n}} \mathrm{c}_{\mathrm{i}} \ln \mathrm{c}_{\mathrm{j}}
$$

where $\mathrm{R}$ is the gas constant. The proposed limits for the formation of simple phases (i.e., fcc, bcc, and their mixtures, including both ordered/disordered cases) are suggested as: $-22 \leq \Delta \mathrm{H}_{\mathrm{mix}} \leq 7 \mathrm{~kJ} / \mathrm{mol}$, $\delta \leq 8.5$, and $11 \leq \Delta \mathrm{S}_{\text {mix }} \leq 19.5 \mathrm{~J} /(\mathrm{K} \cdot \mathrm{mol})$.

Wang et al. [30] also proposed a new geometric factor $(\gamma)$ that determines the solubility of multicomponent alloys, suggesting that $\gamma$ takes into account the largest and the smallest atoms. Factor $\gamma$ is given by Equation (A4):

$$
\gamma=1-\sqrt{\frac{\left(\mathrm{r}_{\mathrm{s}}+\overline{\mathrm{r}}\right)^{2}-\overline{\mathrm{r}}^{2}}{\left(\mathrm{r}_{\mathrm{s}}+\overline{\mathrm{r}}\right)^{2}}} / \sqrt{\frac{\left(\mathrm{r}_{\mathrm{L}}+\overline{\mathrm{r}}\right)^{2}-\overline{\mathrm{r}}^{2}}{\left(\mathrm{r}_{\mathrm{L}}+\overline{\mathrm{r}}\right)^{2}}}
$$

where $r_{S}$ and $r_{L}$ are the atomic radii for the smallest and largest atom, respectively, and $\bar{r}$ is given by $\overline{\mathrm{r}}=\sum_{\mathrm{i}=1}^{\mathrm{n}} \mathrm{c}_{\mathrm{i}} \mathrm{r}_{\mathrm{i}}$. When $\gamma<1.175$, the obliged limit for determining the solubility of multicomponent alloys is achieved, but this is not the only sufficient criterion.

Moreover, a proposed model based on the use of high-throughput computation analysis of the enthalpies of formation between the binary compounds has been suggested, in order to predict 
single-phase equiatomic HEAs. Based on this approach, Troparevsky et al. [33] suggest that the $\Delta \mathrm{H}_{\mathrm{f}}$ values of the binary components ranging inside the recommended boundaries for simple-phase solid solution formation were $-137<\Delta \mathrm{H}_{\mathrm{f}}<37 \mathrm{meV} / \mathrm{mol}$, regarding a 5-component alloy and were $-232<$ $\Delta \mathrm{H}_{\mathrm{f}}<37 \mathrm{meV} / \mathrm{mol}$ for the refractory systems.

Factor $\Phi$, with $\Phi=\Delta \mathrm{G}_{\mathrm{ss}}|-| \Delta \mathrm{G}_{\max } \mid$, recommended by King et al. [31], incorporates the thermodynamic factor $\Delta \mathrm{G}_{\mathrm{ss}}$ that is the change in Gibbs free energy for the formation of a fully disordered solid solution from a mixture of its individual elements and $\Delta G_{\max }$ factor which is the lowest (intermetallic) or highest (segregated) possible Gibbs free energy obtainable from the formation of binary systems from the constituents of the mixture. According to this theory, a value of $\Phi \geq 1$ suggests a stable solid solution at the systems' melting temperature, whereas a negative $\Phi$ value recommends that the solid solution has positive formation enthalpy and will not be formed.

Guo et al. [64] have also worked on the Valence Electron Concentration (VEC) effect, regarding the stability of fcc or bcc phases in high-entropy systems. In another work [65], they also used both $\Delta \mathrm{H}_{\text {mix }}$ and $\delta$ values in order to predict the phase selection in HEAs, since statistically, solid solutions can be formed when $\delta$ is small enough $(\delta \leq 6.6 \%)$ and $\Delta \mathrm{H}_{\text {mix }}$ is either slightly positive or insignificantly negative $\left(-1.6 \leq \Delta \mathrm{H}_{\text {mix }} \leq 3.2 \mathrm{~kJ} / \mathrm{mol}\right)$.

Finally, Yang and Zhang [32] introduced parameter $\Omega=\mathrm{T}_{\mathrm{m}} \Delta \mathrm{S}_{\text {mix }} / \mid \Delta \mathrm{H}_{\text {mix }}$, (where $\mathrm{T}_{\mathrm{m}}$ is the melting point given by the mixture rule), which describes the competition between $\Delta \mathrm{S}_{\text {mix }}$ and $\Delta \mathrm{H}_{\text {mix }}$ values. Statistically, a solid solution can be formed, when $\Omega \geq 1.1$ and $\delta \leq 6.6 \%$.

Recently, a new thermodynamic criterion to predict the formation of equilibrium intermetallic phases in HEAs at a given temperature was suggested by Senkov et al. [34]. A simple thermodynamic criterion $\mathrm{k}_{1}{ }^{\text {cr }}\left(\mathrm{T}_{\mathrm{A}}\right)$ vs. $\Delta \mathrm{H}_{\mathrm{IM}} / \Delta \mathrm{H}_{\text {mix }}$, where $\mathrm{k}_{1}{ }^{\text {cr }}\left(\mathrm{T}_{\mathrm{A}}\right)=\left(1-\mathrm{k}_{2}\right) \cdot \mathrm{T} \cdot \Delta \mathrm{S}_{\text {mix }} / \Delta \mathrm{H}_{\text {mix }}$ and $\mathrm{k}_{2}=\Delta \mathrm{S}_{\mathrm{IM}} / \Delta \mathrm{S}_{\text {mix }}$, was proposed to predict the type of equilibrium phases (solid solutions or intermetallics) observed in a high-entropy alloy, at a given annealing temperature. As indicated, when the values of $\mathrm{k}_{1}{ }^{\mathrm{cr}}\left(\mathrm{T}_{\mathrm{A}}\right)$ are plotted vs. those of $\Delta \mathrm{H}_{\mathrm{IM}} / \Delta \mathrm{H}_{\mathrm{mix}}$, a clear separation of the solid solution alloys from the intermetallic compounds can be spotted.

\section{References}

1. Miracle, D.B. The physical and mechanical properties of NiAl. Acta Mater. 1993, 41, 649. [CrossRef]

2. Ferrandini, P.; Batista, W.W.; Caram, R. Influence of Growth Rate on the Microstructure and Mechanical Behaviour of a NiAl-Mo Eutectic Alloy. J. Alloy. Compd. 2004, 381, 91-98. [CrossRef]

3. Walter, J.L.; Cline, H.E. The Effect of Solidification Rate on Structure and High-Temperature Strength of the Eutectic NiAl-Cr. Metall. Mater. Trans. 1970, 1, 1221-1229. [CrossRef]

4. Bogner, S.; Hu, L.; Hollad, S.; Hu, W.; Gottstein, G.; Bührig-Polaczek, A. Microstructure of a Eutectic NiAl-Mo Alloy Directionally Solidified using an Industrial Scale and a Laboratory Scale Bridgman Furnace. Int. J. Mater. Res. 2012, 103, 17-23.

5. Hu, L.; Hu, W.; Gottstein, G.; Bogner, S.; Hollad, S.; Bührig-Polaczek, A. Investigation into Microstructure and Mechanical Properties of NiAl-Mo Composites Produced by Directional Solidification. Mater. Sci. Eng. A 2012, 539, 211-222. [CrossRef]

6. Johnson, D.R.; Chen, X.F.; Oliver, B.F.; Noebe, R.D.; Whittenberger, J.D. Directional Solidification and Mechanical Properties of NiAl Single Bond NiAlTa Alloys. Intermetallics 1995, 3, 141-152. [CrossRef]

7. Sheng, L.Y.; Guo, J.T.; Ye, H.Q. Microstructure and mechanical properties of $\mathrm{NiAl-Cr}(\mathrm{Mo}) / \mathrm{Nb}$ eutectic alloy prepared by injection-casting. Mater. Des. 2009, 30, 964-969. [CrossRef]

8. Wen, Y.H.; Lill, J.V.; Chen, S.L.; Simmons, J.P. A ternary phase-field model incorporating commercial CALPHAD software and its application to precipitation in superalloys. Acta Mater. 2010, 58, 875-885. [CrossRef]

9. Chen, S.T.; Tang, W.Y.; Kuo, Y.F.; Chen, S.Y.; Tsau, C.H.; Shun, T.T.; Yeh, J.W. Microstructure and properties of age-hardenable AlxCrFe1.5MnNi0.5 alloys. Mater. Sci. Eng. A 2010, 527, 5818-5825. [CrossRef]

10. Hsu, C.Y.; Juan, C.C.; Sheu, T.S.; Chen, S.K.; Yeh, J.W. Effect of aluminum content on microstructure and mechanical properties of AlxCoCrFeMo0.5Ni high- entropy alloys. J. Met. 2013, 65, 1840-1847. 
11. Hsu, C.Y.; Sheu, T.S.; Yeh, J.W.; Chen, S.K. Effect of iron content on wear behavior of AlCoCrFexMo0.5Ni high-entropy alloys. Wear 2010, 268, 653-659. [CrossRef]

12. Wu, J.M.; Lin, S.J.; Yeh, J.W.; Chen, S.K.; Huang, Y.S.; Chen, H.C. Adhesive wear behavior of AlxCoCrCuFeNi high-entropy alloys as a function of aluminum content. Wear 2006, 261, 513-519. [CrossRef]

13. Chuang, M.H.; Tsai, M.H.; Wang, W.R.; Lin, S.J.; Yeh, J.W. Microstructure and wear behavior of AlxCo1.5CrFeNi1.5Tiy high-entropy alloys. Acta Mater. 2011, 59, 6308-6317. [CrossRef]

14. Munitz, A.; Meshi, L.; Kaufman, M.J. Heat treatments' effects on the microstructure and mechanical properties of an equiatomic Al-Cr-Fe-Mn-Ni high entropy alloy. Mater. Sci. Eng. A 2017, 689, 384-394. [CrossRef]

15. Tang, B.; Cogswell, D.A.; Hu, G.; Milenkovic, S.; Cui, Y. The formation mechanism of eutectic microstructures in NiAl-Cr composites. Phys. Chem. Chem. Phys. 2016, 18, 19773-19786. [CrossRef]

16. Duprin, N.; Ansara, I.; Sundman, B. Thermodynamic Re-Assessment of the Ternary System Al-Cr-Ni. Calphad 2001, 25, 279-298. [CrossRef]

17. Bei, H.; George, E.P. Microstructures and Mechanical Properties of a Directionally Solidified NiAl-Mo Eutectic Alloy. Acta Mater. 2005, 53, 69-77. [CrossRef]

18. Zhang, J.F.; Shen, J.; Shang, Z.; Feng, Z.R.; Wang, L.S.; Fu, H.Z. Microstructure and Room Temperature Fracture Toughness of Directionally Solidified NiAl-Mo Eutectic in situ Composites. Intermetallics 2012, 21, 18-25. [CrossRef]

19. Chen, X.F.; Johnson, D.R.; Noebe, R.D.; Oliver, B.F. Deformation and Fracture of a Directionally Solidified NiAl-28Cr-6Mo Eutectic Alloy. J. Mater. Res. 1995, 10, 1159-1170. [CrossRef]

20. Whittenberger, J.D.; Raj, S.V.; Locci, I.E.; Salem, J.A. Effect of Growth Rate on Elevated Temperature Plastic Flow and Room Temperature Fracture Toughness of Directionally Solidified NiAl-31Cr-3Mo. Intermetallics 1999, 7, 1159-1168. [CrossRef]

21. Raj, S.V.; Locci, I.E. Microstructural Characterization of a Directionally-Solidified Ni-33 (at.\%) Al-31Cr-3Mo Eutectic Alloy as a Function of Withdrawal Rate. Intermetallics 2001, 9, 217-227. [CrossRef]

22. Raj, S.V.; Locci, I.E.; Salem, J.A.; Pawlik, R.J. Effect of Directionally Solidified Microstructures on the Room-Temperature Fracture-toughness Properties of Ni-33(at.\%)Al-33Cr-1Mo and Ni-33(at.\%)Al-31Cr-3Mo Eutectic Alloys Grown at Different Solidification Rates. Metall. Mater. Trans. A 2002, 33, 597-612. [CrossRef]

23. Shang, Z.; Shen, J.; Wang, L.; Du, Y.; Xiong, Y.; Fu, H. Investigations on the Microstructure and Room Temperature Fracture Toughness of Directionally Solidified NiAl-Cr(Mo) Eutectic Alloy. Intermetallics 2015, 57, 25-33. [CrossRef]

24. Peng, J.; Franke, P.; Seifert, H.J. Experimental Investigation and CALPHAD Assessment of the Eutectic Trough in the System NiAl-Cr-Mo. J. Phase Equilib. Diffus. 2016, 37, 592-600. [CrossRef]

25. Guo, J.; Wang, Z.; Sheng, L.; Zhou, L.; Yuan, C.; Chen, Z.; Song, L. Wear properties of NiAl based materials. Prog. Nat. Sci. Mater. Int. 2012, 22, 414-425. [CrossRef]

26. Mathiou, C.; Giorspyros, K.; Georgatis, E.; Karantzalis, A.E. Microstructural verification of the theoretically predicted morphologies of the NiAl-Cr pseudo-binary alloy systems and NiAl-Cr eutectic structure modification by Mo addition. SN Appl. Sci. 2019, 1, 1292. [CrossRef]

27. Sheng, L.; Zhang, W.; Guo, J.; Ye, H. Microstructure and mechanical properties of Hf and Ho doped NiAl-Cr (Mo) near eutectic alloy prepared by suction casting. Mater. Charact. 2009, 60, 1311-1316. [CrossRef]

28. Sheng, L.; Wang, L.; Xi, T.; Zheng, Y.; Ye, H. Microstructure, precipitates and compressive properties of various holmium doped NiAl/Cr (Mo, Hf) eutectic alloys. Mater. Des. 2011, 32, 4810-4817. [CrossRef]

29. Zhang, Y.; Zhou, Y.J.; Lin, J.P.; Chen, G.L.; Liaw, P.K. Solid solution phase formation rules for multi-component alloys. Adv. Eng. Mater. 2008, 10, 534-538.

30. Wang, Z.; Huang, Y.; Yang, Y.; Wang, J.; Liu, C.T. Atomic-size effect and solid solubility of multicomponent alloys. Scr. Mater. 2015, 94, 28-31. [CrossRef]

31. King, D.J.M.; Middleburgh, S.C.; McGregor, A.G.; Cortie, M.B. Predicting the formation and stability of single phase high-entropy alloys. Acta Mater. 2016, 104, 172-179. [CrossRef]

32. Yang, X.; Zhang, Y. Prediction of high-entropy stabilized solid-solution in multi-component alloys. Mater. Chem. Phys. 2012, 132, 233-238. [CrossRef]

33. Troparevsky, M.C.; Morris, J.R.; Kent, P.R.C.; Lupini, A.R.; Stocks, G.G. Criteria for predicting the formation of single-phase high-entropy alloys. Phys. Rev. X 2015, 5, 011041-1-011041-6.

34. Senkov, O.N.; Miracle, D.B. A new thermodynamic parameter to predict formation of solid solution or intermetallic phases in high entropy alloys. J. Alloys Compd. 2016, 658, 603-607. [CrossRef] 
35. Pickering, E.J.; Jones, N.G. High-entropy alloys: A critical assessment of their founding principles and future prospects. Int. Mater. Rev. 2016, 61, 183-202. [CrossRef]

36. Poulia, A.; Georgatis, E.; Mathiou, C.; Karantzalis, A.E. Phase segregation discussion in a Hf25Zr30Ti20Nb15V10 high entropy alloy: The effect of the high melting point element. Mater. Chem. Phys. Mater. 2018, 210, 251-258. [CrossRef]

37. Mathiou, C.; Poulia, A.; Georgatis, E.; Karantzalis, A.E. Microstructural features and dry-Sliding wear response of MoTaNbZrTi high entropy alloy. Mater. Chem. Phys. Mater. 2018, 210, 126-135. [CrossRef]

38. Karantzalis, A.E.; Poulia, A.; Georgatis, E.; Petroglou, D.; Mathiou, C. New MoWHfZrTi refractory high entropy alloy system: A microstructural verification of phase formation criteria approach. Res. Rep. Met. 2017, 1, 1-6.

39. Boettinger, W.J.; Banerjee, D.K. Physical Metallourgy, 5th ed.; Laughlin, D.E., Hono, K., Eds.; Elsevier: Amsterdam, The Netherlands, 2014; Volume 1, p. 668. ISBN 978-0-444-59598-0.

40. Mathiou1, C.; Ganara1, D.; E. Georgatis1, E.; Poulia1, A.; Lentzaris1, K.; Karantzalis1, A.E. Adjustment of hardness of $(\mathrm{CrFeMn})_{\mathrm{x}}\left(\mathrm{Ni}_{\mathrm{y}} \mathrm{Al}\right)_{1-\mathrm{x}},(\mathrm{y}=1,3$ and $\mathrm{x}=0.6,0.72,0.80)$ High Entropy Alloys by Deliberate Control of Intermetallic Phase Formation: Microstructural Evolution, Hardness and Dry-Sliding Wear Response. Met. Mater. Int. 2020, 1-18. [CrossRef]

41. Shang, Z.; Shen, J.; Zhang, J.; Wang, L.; Wang, L.; Fu, H. Effect of microstructures on the room temperature fracture toughness of NiAl-32Cr-6Mo hypereutectic alloy directionally solidified at different withdrawal rates. Mater. Sci. Eng. A 2014, 611, 306-312. [CrossRef]

42. Yang, J.-M.; Jeng, S.M.; Bain, K.; Amato, R.A. Microstructure and mechanical behavior of in-situ directional solidified NiAl/Cr(Mo) eutectic composite. Acta Mater. 1997, 45, 295-305. [CrossRef]

43. Tang, L.-Z.; Zhang, Z.-G.; Li, S.S.; Gong, S.-K. Mechanical behaviors of NiAl-Cr(Mo)-based near eutectic alloy with Ti, Hf, $\mathrm{Nb}$ and $\mathrm{W}$ additions. Trans. Nonferrous Met. Soc. China 2010, 20, 212-216. [CrossRef]

44. Wang, L.; Shen, J.; Zhang, Y.; Xu, H.; Fu, H. Microstructure and mechanical properties of NiAl-based hypereutectic alloy obtained by liquid metal cooling and zone melted liquid metal cooling directional solidification techniques. J. Mater. Res. 2016, 31, 646-654. [CrossRef]

45. Guo, S.; Chun, N.; Liu, C.T. Sunflower-like Solidification Microstructure in a Near-eutectic High-entropy alloy. Mater. Res. Lett. 2013, 1, 228-232. [CrossRef]

46. Goetzinger, R.; Barth, M.; Herlach, D.M. Growth of lamellar eutectic dendrites in undercooled melts. J. Appl. Phys. 1998, 84, 1643-1649. [CrossRef]

47. Li, M.; Kuribayashi, K. Free Solidification of Undercooled Eutectics. Mater. Trans. 2006, 47, $2889-2897$. [CrossRef]

48. Available online: http://resource.npl.co.uk/mtdata/phdiagrams/crmo.htm (accessed on 28 May 2020).

49. Mei, Q.; Li, J. Dependence of Liquid Supercooling on Liquid Overheating Levels of Al Small Particles. Materials 2016, 9, 7. [CrossRef]

50. Yang, B.; Perepezko, J.H.; Schmelzer, J.W.P.; Gao, Y.; Schick, C. Dependence of crystal nucleation on prior liquid overheating by differential fast scanning calorimeter. J. Chem. Phys. 2014, 140, 104513-1-104513-7. [CrossRef]

51. Available online: http://resource.npl.co.uk/mtdata/phdiagrams/moni.htm (accessed on 28 May 2020).

52. Available online: http://resource.npl.co.uk/mtdata/phdiagrams/almo.htm (accessed on 28 May 2020).

53. Demirtas, H.; Gungor, A. Effect of alloying elements on the microstructure and mechanical properties of NiAl-Cr(Mo) eutectic alloy. Sci. Proc. XII Int. Congr. Macnines Technol. Mater. 2015, 2, 4-8.

54. Tsai, M.; Yeh, J.W. High-Entropy Alloys: A Critical Review. J. Mater. Res. Lett. 2014, 2, 107-123. [CrossRef]

55. Cantor, B.; Chang, I.T.H.; Knight, P.; Vincent, A.J.B. Microstructural development in equiatomic multicomponent alloys. Mater. Sci. Eng. A 2004, 375, 213-218. [CrossRef]

56. Senkov, O.N.; Miracle, D.B.; Chaput, K.J.; Couzinie, J.-P. Development and exploration of refractory high entropy alloys-A review. J. Mater. Res. 2018, 33, 3092-3128. [CrossRef]

57. Booser, E.R. Tribology Data Handbook; CRC Press: New York, NY, USA, 1997.

58. Glascott, J.; Stott, F.H.; Wood, G.C. The Effectiveness of Oxides in Reducing Sliding Wear of Alloys. Oxid. Met. 1985, 24, 99-114. [CrossRef]

59. Stott, F.H.; Wood, G.C. The influence of Oxides on the Friction and Wear of Alloys. Tribol. Int. 1978, 11, 211-218. [CrossRef] 
60. Moridi, A.; Ruan, H.; Zhang, L.C.; Liu, M. Residual stresses in thin film systems: Effects of lattice mismatch, thermal mismatch and interface dislocations. Int. J. Solids Struct. 2013, 50, 3562-3569. [CrossRef]

61. Kirkpatrick, R.J. Crystal growth from the melt-A review. Am. Miner. 1975, 60, 798-814.

62. Sheng, L.Y.; Yang, F.; Xi, T.F.; Guo, J.T. Investigation on microstructure and wear behavior of the $\mathrm{NiAl}-\mathrm{TiC}-\mathrm{Al}_{2} \mathrm{O}_{3}$ composite fabricated by self-propagation high-temperature synthesis with extrusion. J. Alloy. Compd. 2013, 554, 182-188. [CrossRef]

63. Sheng, L.Y. Microstructure, mechanical and tribological properties of the rapidly solidified NiAl/Cr (Mo, Dy) hypoeutectic alloy. Mater. Sci. Forum 2016, 849, 590-596. [CrossRef]

64. Guo, S.; Ng, C.; Lu, J.; Liu, C.T. Effect of valence electron concentration on stability of fcc or bcc phase in high entropy alloys. J. Appl. Phys. 2011, 109, 103505-1-103505-5. [CrossRef]

65. Guo, S.; Hu, Q.; Ng, C.; Liu, C.T. More than entropy in high entropy alloys: Forming solid solutions or amorphous phase. Intermetallics 2013, 41, 96-103. [CrossRef]

(C) 2020 by the authors. Licensee MDPI, Basel, Switzerland. This article is an open access article distributed under the terms and conditions of the Creative Commons Attribution (CC BY) license (http://creativecommons.org/licenses/by/4.0/). 